Radioisotope Power Systems Materials Production and Technology Program Materials Science and Technology Division

\title{
ANNUAL TECHNICAL PROGRESS REPORT OF RADIOISOTOPE POWER SYSTEMS MATERIALS PRODUCTION AND TECHNOLOGY PROGRAM TASKS FOR OCTOBER 1, 2006 THROUGH SEPTEMBER 30, 2007
}

\section{J. F. King}

February 2008

Prepared for Department of Energy Office of Radioisotope Power Systems

AF 0110100

Prepared by

OAK RIDGE NATIONAL LABORATORY

Oak Ridge, Tennessee 37831-6079

managed by

UT-BATTELLE, LLC

for the

U.S. DEPARTMENT OF ENERGY

under contract DE-AC05-00OR22725 


\section{CONTENTS}

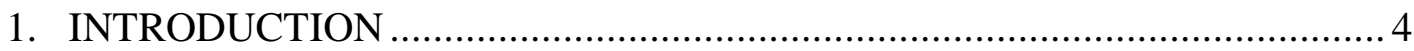

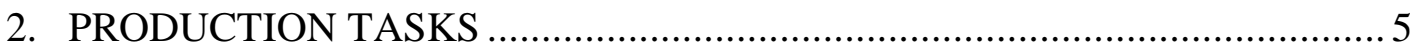

2.1 CARBON-BONDED CARBON FIBER ….................................... 5

2.1 .1 Background ............................................................. 5

2.1.2 CBCF Production in Fiscal Year 2007 .................................. 5

2.1.3 CBCF Shipments in FY 2007.............................................. 5

2.1.4 Status of CBCF Production Capability: Personnel,

Facilities, and Raw Materials ........................................... 5

2.2 IRIDIUM ALLOY BLANK AND FOIL PRODUCTION .................... 6

2.2.1 Iridium Powder Procurement .............................................. 6

2.2.2 Blank Production............................................................. 8

2.2.2.1 Blank Production from GR9 Ingot............................. 8

2.2.2.2 Blank Production from KR4 Ingot............................ 8

2.2.3 Iridium Alloy Foil Production.......................................... 8

2.2.4 Deviation Requests ...................................................... 8

2.2.5 Transfers to CVS Task...................................................... 9

2.2.6 Training .......................................................................... 9

2.2.7 Processing Equipment.................................................. 9

2.2.8 Preparation of Iridium Reference Materials for Chemical Analyses ............................................................ 9

2.2.9 Trend Analysis of Thickness Uniformity in Iridium Alloy Foil Production .................................................... 11

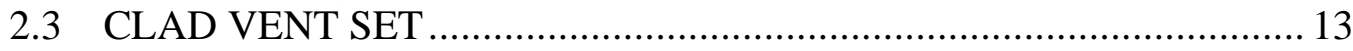

2.3.1 Maintenance Production Summary ...................................... 13

2.3.2 Nonconformance Report, Special Instruction Deviation Request, and Deviation Request Summaries ....................... 13

2.3.3 Decontamination Cover Tooling .......................................... 14

2.3.4 Dimensional Inspection Evaluation for Foil Components ........ 14

2.3.5 Cup Forming Evaluations ................................................ 15

2.3.6 Carbon and Oxygen Back-up Analytical Qualifications .......... 20

2.3.7 Frit Vent Powder Evaluation................................................. 20

2.4 IRIDIUM POWDER AND INVENTORY MANAGEMENT .............. 21

2.4.1 Iridium Demand and Supply Schedule .................................. 21

2.4.2 Annual Write-Off ................................................................... 23

2.4.3 Iridium Accountability Reviews......................................... 23

2.4.4 Shipment of Iridium.................................................... 23

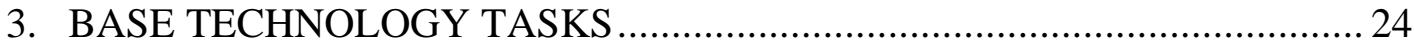

3.1 ALLOY CHARACTERIZATION.................................................. 24

3.1.1 "Low-temperature" tensile impact ductility of DOP-26 iridium............................................................... 24

3.1.2 Effects of temperature, strain rate, and orientation on the tensile strength and ductility of DOP-26 iridium........... 24

3.1.3 Effects of copper on the tensile impact ductility of DOP-26

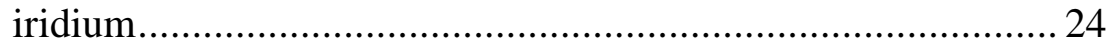


3.1.4 Effects of oxygen on the elevated-temperature tensile ductility of Ta-10W

3.2 ORNL CHARACTERIZATION OF MIN-K TE-1400 …...................... 25

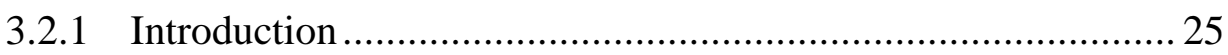

3.2.2 Experimental Procedures …………………........................... 26

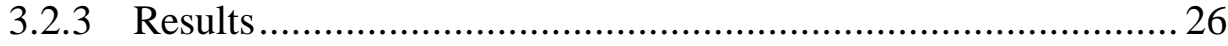

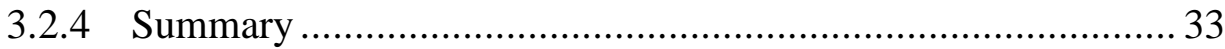




\subsection{INTRODUCTION}

The Office of Radioisotope Power Systems of the Department of Energy (DOE) provides Radioisotope Power Systems (RPS) for applications where conventional power systems are not feasible. For example, radioisotope thermoelectric generators were supplied by the DOE to the National Aeronautics and Space Administration for deep space missions including the Cassini Mission launched in October of 1997 to study the planet Saturn. For the Cassini Mission, ORNL produced carbon-bonded carbon fiber (CBCF) insulator sets, iridium alloy blanks and foil, and clad vent sets (CVS) used in the generators. The Oak Ridge National Laboratory (ORNL) has been involved in developing materials and technology and producing components for the DOE for more than three decades.

This report reflects program guidance from the Office of Radioisotope Power Systems for fiscal year (FY) 2007. Production activities for prime quality (prime) CBCF insulator sets, iridium alloy blanks and foil, and CVS are summarized in this report. Technology activities are also reported that were conducted to improve the manufacturing processes, characterize materials, or to develop information for new radioisotope power systems. 


\subsection{PRODUCTION TASKS}

\subsection{CARBON-BONDED CARBON FIBER}

\subsubsection{Background}

The Carbon Bonded Carbon Fiber $(\mathrm{CBCF})$ production facilities have been operated in a production maintenance mode since the Cassini campaign to produce prime insulators. Dedicated facilities for CBCF production remain in the Carbon Materials Technology Laboratory at ORNL. During much of the 1990s CBCF production was directed at making experimental variations of $\mathrm{CBCF}$ that explored the potential for improved insulating attributes at very high temperatures. The effect of brief excursions to reentry temperatures was also explored. Sleeves produced in FY 2000 were the first to be fully characterized as prime in nearly a decade. Resolution of issues related to elevated impurities in CBCF allowed for the continued production of prime insulators in FY 2003 through FY 2007. Prime insulation sets were shipped to INL in FY 2006 and FY 2007 to support the Mars Science Laboratory Mission.

\subsubsection{CBCF Production in FY 2007}

More than thirty-two additional prime CBCF insulation sets were produced in FY 2007 to support future RPS Program missions. Production yields were greater than $90 \%$. Numerous Quality Assurance Surveillances were conducted at ORNL including: Instrument Calibration, Dimensional Inspection of Insulators, Radiographic and Personnel Training. Analytical Chemistry Organization Procedure "Spark Source Mass Spectrographic Determination of Impurities in Carbon" was revised to incorporate the use of new standard reference materials and meet more explicit safety requirements. The radiographic inspection facility was relocated on the ORNL campus. An audit of these facilities and operating procedures was performed on behalf of DOE.

\subsubsection{CBCF Shipments in FY 2007}

Forty-two prime CBCF Sleeves and 78 prime CBCF Discs were shipped to INL in June to support the Mars Science Lab Mission. An additional twelve prime CBCF Sleeves and fifty-seven prime $\mathrm{CBCF}$ Discs were certified and readied for shipment pending DOE acceptance review.

\subsubsection{Status of CBCF Production Capability: Personnel, Facilities, and Raw Materials}

Key personnel including the task manager, two principal technicians and one machinist remain committed to the near-term (5+years) production of $\mathrm{CBCF}$ insulators. Additionally, personnel involved in inspection and qualification testing will be available to support near-term production. 
Facilities and equipment used for the production of CBCF are kept in good working order through annual production activities and continuous maintenance and calibrations. In FY 2007 a state-of-the-art control and data logging system was procured for installation on the carbonization furnace in FY 2008.

The current inventory of critical materials includes approximately $500 \mathrm{lbs}$ of chopped rayon fiber ( 120 molding runs) and approximately150 lbs of Durez 22352 Resin ( 250 molding runs). The current lot of Durez resin was received in May 2003 and qualified for producing prime insulators in FY 2004. In each of the past four years, more than twenty-four prime insulator sets were produced. A beneficial trend in compressive strength was noted in that the strength increased in each successive year. This effect may be attributed to cross linking in the resin resulting in greater accumulation of bonding carbon at fiber intersections. There is likely a limit to the beneficial effect of cross linking. An investigation into aging of Durez 22352 resin is underway. Vacuum packing with refrigerated storage is under consideration.

\subsection{IRIDIUM ALLOY BLANK AND FOIL PRODUCTION}

The goals for this activity are to produce prime blanks and foil under full configuration control, maintain production capability and to supply materials needed for clad vent set demonstration and maintenance activities. During FY 200730 blanks from the GR9 ingot were boxed and placed in secure storage with an approved data package. Ninety nine pieces of foil were produced. Eighty two $\mathrm{kg}$ of iridium powder were returned from the refining of scrap iridium. A new $4 \mathrm{Hi} / 2 \mathrm{Hi}$ rolling mill was qualified for iridium processing. Upgraded control systems were installed for the vacuum arc remelting (VAR) furnace and the electron beam (EB) melting furnace. Two new button arc melting furnaces were fabricated and assembled to replace obsolete equipment.

\subsubsection{Iridium Powder Procurement}

Iridium scrap sent for commercial refining in FY 2006 was refined in FY2007. Forty $\mathrm{kg}$ was received in June and an additional $42 \mathrm{~kg}$ in July of FY 2007. The refining contract required that the powder returned would meet a commercial specification because no refiner would accept the program's specification for powder in the contract. Powder lots for delivery from the vendor were selected on the basis of the vendor's analysis. Subsequent acceptance of the powder for program use was based on established procedures. All of the powder received in June was analyzed and found to meet specification. The powder exhibited physical characteristics different from powder previously received; in particular it showed an apparent density at lease twice that of iridium powder previously used. Scanning electron micrographs of the powder are shown in Figure 1. A single compact was pressed using this powder and the compact was pressed without difficulty.

The second shipment of $42 \mathrm{~kg}$ contained about $12 \mathrm{~kg}$ of powder from the refining operation and the remainder was typical of powder purchased in previous years. Analysis for impurities by glow discharge mass spectrometry (GDMS) was completed for samples from the 10 jars of this iridium powder. Four of the samples, representing $15 \mathrm{~kg}$, showed 
ruthenium content above the specified limit of $50 \mu \mathrm{g} / \mathrm{g}$. A nonconformance report (NCRIrBF-2166) was prepared for this powder with a recommended disposition for use as-is. The justification for the recommendation is that blending with other powders will produce the M-batch of $82 \mathrm{~kg}$, with an average $\mathrm{Ru}$ content of $17 \mu \mathrm{g} / \mathrm{g}$. This value is below the specification limit for blank and foil of $50 \mu \mathrm{g} / \mathrm{g}$ and is a typical composition for production blanks.
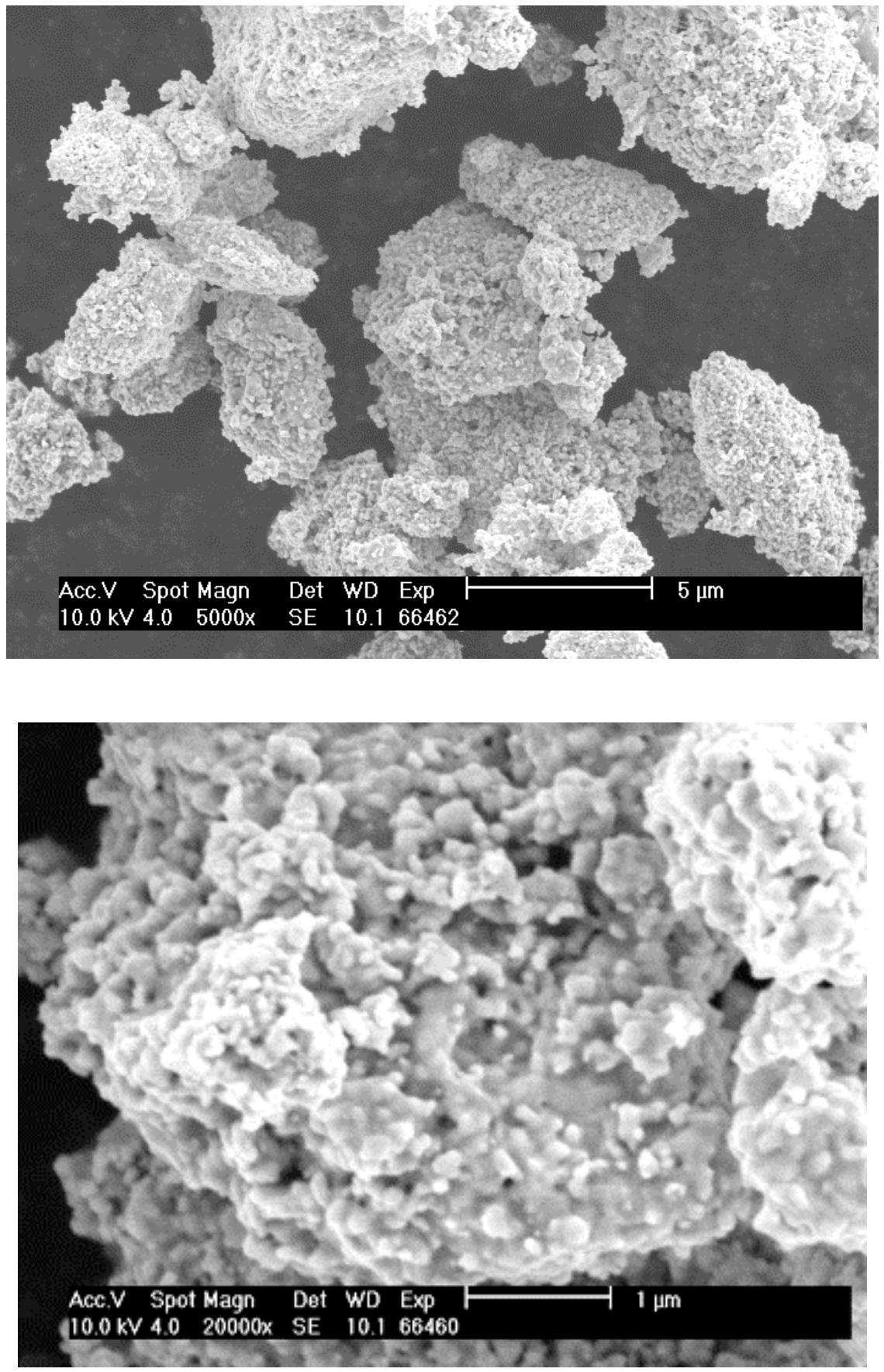

Figure 1. Scanning electron micrographs of refined iridium powder. 


\subsubsection{Blank Production}

\subsubsection{Blank Production from GR9 Ingot}

A data package was prepared for 30 blanks from the GR9 ingot. The blanks, which had been fabricated in FY 2006, were placed in storage with the approved data package in June 2007.

\subsubsection{Blank Production from KR4 Ingot}

The KR4 electrode was successfully melted by VAR in October 2006.

The ingot was machined and molybdenum extrusion can was prepared. Hot extrusion of the KR4 ingot was successfully completed in January 2007. The extrusion was stored for future production of blanks.

\subsubsection{Iridium Alloy Foil Production}

A total of 7 ingots were melted and drop-cast for foil production. The ingots, identified as EFR301 and EFR303 through EFR308 were produced from melt stock consisting of ER10 recycle materials and electron-beam melted buttons from $\mathrm{K}$ and $\mathrm{F}$ batches. Another ingot, EFR302 was scrapped after becoming chemically contaminated (NCR IrBF-2165). The contamination was attributed to an uncontrolled arc associated with a displaced metal screen in the melt chamber. The screen attachment was improved and melting of the ingots continued without further difficulties. Two new furnaces for button arc melting and drop-casting were designed and fabricated. The new design has the screen located much further from the melting hearth to avoid the recurrence of this type of uncontrolled arc.

Molybdenum frames were machined for use in rolling of 7 ingots. The seven ingots were given a homogenization heat treatment, and placed in the frames for initial hot rolling. The frames remained attached through the in-process recrystallization heat treatment. Materials from 7 drop-cast ingots were rolled to approximately $0.66-\mathrm{mm}$, cleaned and recrystallized by vacuum heat treatment. The sheet materials were warm rolled to 0.2$\mathrm{mm}$ thickness. The sheets were cut, trimmed, and cleaned in preparation for further rolling. The sheets were cold rolled from a thickness of $0.2 \mathrm{~mm}$ to the final $0.13 \mathrm{~mm}$ thickness. These foils passed dimensional inspection. They were cleaned and given a recrystallization heat treatment. Samples were prepared for chemical and metallographic analysis. The foil materials from all seven ingots were found to meet requirements for chemical composition and metallographic structure.

\subsubsection{Deviation Requests}

A deviation request (DR-Ir-216) for processing of iridium alloy foil was approved and distributed. The request updated the equipment lists for rolling and heat treating of foil and made editorial changes in three foil procedures. The $4 \mathrm{Hi} / 2 \mathrm{Hi}$ mill was added to the list of equipment for use in foil rolling. 


\subsubsection{Transfers to CVS Task}

Corrugated iridium alloy foil, with a total weight of 798 grams, was transferred to the CVS task in January 2007. The corrugated foil is used as furnace liner during air burnoff of iridium alloy CVS components. The foil was produced from the scrap iridium extrusion MS3. The foil was rolled, cleaned, recrystallized, and corrugated. The corrugated foil received a final acid cleaning.

A total of 21 blanks produced from iridium alloy scrap were provided to the CVS task for use in forming and tooling studies. The blanks received ultrasonic inspection and had previously passed dimensional inspection.

\subsubsection{Training}

Two additional technicians were trained in the procedure for rolling of iridium alloy foil. One additional technician was trained in sampling and cleaning of iridium alloy foil.

\subsubsection{Processing Equipment}

An upgraded control system for the Vacuum Arc Remelting furnace was installed under the supervision of a representative of the furnace vendor. The acceptance testing of the new control system was completed in accordance with the equipment purchase specification. Training of two technicians in the operation of the equipment was also completed. All melt trials, including a total of four stainless steel melts and one niobium melt, were successfully performed. A revised standard operating guideline for the furnace (MET-MatP-SOP-120 rev. 3) was issued in April 2007. The new control system was purchased with FY2006 capital funds.

Installation of phase I of an upgraded control system for the electron-beam melting furnace was completed. Phase I includes controls for beam deflection. The furnace operators were trained in its use by a vendor representative. Acceptance testing, including melting of iridium alloy scrap materials, was also successfully completed. Iridium buttons were successfully melted entirely under automated control and no operator adjustments to the beam deflection were necessary, as was the case with the old control system. The new control system was purchased with FY2006 capital funds. Phase II of the upgrade, including vacuum systems controls, is anticipated in FY 2009.

The development of optimized control parameters for the melting of iridium alloy buttons and re-qualification of the furnace for iridium production is planned for FY 2008.

\subsubsection{Preparation of Iridium Reference Materials for Chemical Analyses}

Reference materials for carbon and oxygen analysis were prepared for iridium powder, iridium alloy foil, and iridium alloy blanks. Iridium powders from six jars, with varying sieve fractions, were blended. Each blend was dispensed into 16 vials with 5 grams in each vial. Iridium alloy foil produced for scrap sheet material was sectioned into pieces of about 0.1 gram each and were cleaned using standard methods. The foil pieces were 
blended and stored. Iridium alloy blanks were similarly cut, cleaned, and blended to maximize homogeneity of the samples. Samples were analyzed at the Oak Ridge Y-12 Plant using the currently approved method for carbon with the LECO CS400 instrument. Additional samples were analyzed at a later time. The averaged results of each analysis, identified as week 1 and week 2, are listed in Table 1. Samples were also analyzed for oxygen using the current method with the LECO TC436 instrument, as well as with a newer LECO TCH600 instrument. The results of the oxygen analyses are listed in Table 2. The remaining portions of the reference samples were retained for comparison of carbon and oxygen analyses performed with various analytical instruments and at various sites.

Table 1. Carbon Analyses of Iridium Reference Materials Using LECO CS400 Instrument at Oak Ridge Y-12 Plant

\begin{tabular}{|l|c|c|c|c|}
\hline & & & \multicolumn{2}{c|}{ Carbon, ppm } \\
\hline \multicolumn{1}{|c|}{ Form } & ID & Mesh & Week 1 & Week 2 \\
\hline \hline & & & & \\
\hline Powder & 6-1A & $-325 / 400$ & 24 & 29 \\
\hline Powder & 6-1B & $-325 / 400$ & 20 & 22 \\
\hline Powder & $91-0087-4 \mathrm{~B}$ & $-325 / 400$ & 16 & 18 \\
\hline Powder & $92-32-5$ ABC & $-325 / 400$ & 16 & 20 \\
\hline Powder & OIR 03/01A-5 & -100 & 30 & 31 \\
\hline Powder & $12800 / 21-B$ & as-received & 31 & 34 \\
\hline Foil & MS3-2-C & n/a & 8.0 & 5.5 \\
\hline Blank & MS3-5-C & n/a & 6.5 & 5.7 \\
\hline
\end{tabular}

Table 2. Oxygen Analyses of Iridium Reference Materials Using LECO C436 and TCH600 Instruments at Oak Ridge Y-12 Plant.

\begin{tabular}{|l|c|c|c|c|c|c|}
\hline & & & \multicolumn{2}{c|}{ Oxygen, ppm } & \multicolumn{2}{c|}{ Oxygen, ppm } \\
\hline & & & \multicolumn{2}{c|}{ TC436 Instrument } & \multicolumn{2}{c|}{ TCH600 Instrument } \\
\hline \multicolumn{1}{|c|}{ Form } & ID & Mesh & Week 1 & Week 2 & Week 1 & Week 2 \\
\hline & & & & & & \\
\hline Powder & 6-1A & $-325 / 400$ & 296 & 293 & 301 & 306 \\
\hline Powder & 6-1B & $-325 / 400$ & 293 & 308 & 313 & 294 \\
\hline Powder & $91-0087-4 B$ & $-325 / 400$ & 271 & 269 & 280 & 279 \\
\hline Powder & $92-32-5$ ABC & $-325 / 400$ & 412 & 411 & 423 & 436 \\
\hline Powder & OIR 03/01A-5 & -100 & 422 & 427 & 441 & 406 \\
\hline Powder & 12800/21-B & as-rec & 337 & 339 & 363 & 335 \\
\hline Foil & MS3-2-Ox & n/a & 4.7 & 4.2 & & \\
\hline Blank & RS12-Ox & n/a & 1.3 & 2.1 & & \\
\hline
\end{tabular}




\subsubsection{Trend Analysis of Thickness Uniformity in Iridium Alloy Foil Production}

The new Fenn 4Hi/2Hi rolling mill was qualified for use in iridium alloy blank and foil production during FY 2007 and used for production of foil from ingots EFR 301 and EFR 303 through EFR 308. The mill is used in the $4 \mathrm{Hi}$ configuration for rolling of foil to final thickness and in the $2 \mathrm{Hi}$ configuration for flattening of sheet material during rolling of materials for both blank and foil production. The mill had been installed and acceptance tested to the requirements of the purchase specification during FY 2006. After acceptance of the mill, 24 additional foils from MS3 iridium alloy scrap material were rolled to further characterize the capability of the mill. The results of these trials [ref. 1] showed superior performance to the mill previously used and qualified the new mill for use in foil rolling. The use of the mill in the $2 \mathrm{Hi}$ configuration for flattening of sheets was approved under DR-Ir-216 in November 2006 on the basis of the results of the equipment acceptance testing.

The processing of the foil is described in section 2.2.3 above. After designation of some foil materials for chemical and metallographic analysis, each of the seven ingots produced between 11 and 17 foils. The thickness measurements for the foils are summarized in Table 3. A minimum and maximum thickness value for each foil is obtained during the dimensional inspection for certification, following the first cleaning of the rolled foil. The absolute minimum and maximum measured thickness for all foils from each ingot are listed in the third and fourth columns of Table 3. The absolute minimum thickness value for all of 99 foils is 0.113 and the absolute maximum thickness value is $0.134 \mathrm{~mm}$. The minimum thickness value for all foils from a single ingot ranges from $0.113 \mathrm{~mm}$ to $0.117 \mathrm{~mm}$. The maximum thickness value for all foils from a single ingot ranges from 0.130 to $0.134 \mathrm{~mm}$. The averages of the minimum values and the averages of the maximum values from all foils from a single ingot are listed in columns 5 and 6 of Table 3. The average variation within the thickness for all foils from each ingot is listed in the last column of Table 3. It is apparent that variability is somewhat greater for foils from ingot EFR301. This is attributed to improved dimensional control during rolling of subsequent foils and more careful trimming of the foils during rolling and prior to inspection.

Table 3. Foil Thickness Values for Production Ingots Processed in FY 2007

\begin{tabular}{lcccccc}
\hline Ingot No. & $\begin{array}{c}\text { No. } \\
\text { foils }\end{array}$ & $\begin{array}{c}\text { Minimum } \\
\text { for ingot } \\
\mathrm{mm}\end{array}$ & $\begin{array}{c}\text { Maximum } \\
\text { for ingot } \\
\mathrm{mm}\end{array}$ & $\begin{array}{c}\text { Foil avg. } \\
\text { minimum } \\
\mathrm{mm}\end{array}$ & $\begin{array}{c}\text { Foil avg. } \\
\text { maximum } \\
\mathrm{mm}\end{array}$ & $\begin{array}{c}\text { Foil avg. } \\
\text { variation } \\
\mathrm{mm}\end{array}$ \\
\hline EFR301 & 15 & 0.113 & 0.131 & 0.116 & 0.128 & 0.012 \\
EFR303 & 15 & 0.116 & 0.130 & 0.120 & 0.126 & 0.008 \\
EFR304 & 17 & 0.117 & 0.133 & 0.121 & 0.128 & 0.007 \\
EFR305 & 15 & 0.118 & 0.132 & 0.122 & 0.129 & 0.007 \\
EFR306 & 12 & 0.118 & 0.133 & 0.122 & 0.129 & 0.008 \\
EFR307 & 11 & 0.118 & 0.134 & 0.122 & 0.130 & 0.008 \\
EFR308 & 14 & 0.117 & 0.134 & 0.121 & 0.129 & 0.008 \\
& & & & & & \\
Average & & 0.117 & 0.132 & 0.121 & 0.128 & 0.008 \\
\hline
\end{tabular}


The variability of thickness for foils from different lots of foil is summarized in Table 4 . The range in thickness, or the difference between the maximum thickness for all foils in a lot and the minimum thickness for all foils in the same lot, is listed in the third column of the table. The average of the difference between the maximum and minimum thickness within a single foil is listed in the fourth column of the table. In order to facilitate comparison, a lot for production foils is defined as all foils listed on a single production traveler sheet. In this way each lot contains at least 24 foils. It is seen that the thickness range for the current production EFR foils is similar to that for the 24 trial foils processed previously for the qualification of the mill. A comparison with the GFR foils, the most recent previous foil production lots, or with the average values for all foil production since 1993 shows that foils rolled with the Fenn mill are significantly more uniform in thickness. The range of foil thickness is at least $40 \%$ less than that for foils rolled on the Bliss mill. A comparison of the average thickness variation within a single foil shows smaller values for the Fenn mill as compared to the Bliss mill, with average values of 0.008 or $0.009 \mathrm{~mm}$ for the Fenn mill and 0.009 to 0.012 for the Bliss mill.

\section{Table 4. Trend Analysis for Foil Thickness Values Shows Improved Thickness Uniformity for Foils Rolled on the Fenn 4Hi/2Hi Rolling Mill}

\begin{tabular}{|c|c|c|c|c|c|}
\hline $\begin{array}{l}\text { Mill for } \\
\text { Final } \\
\text { Rolling }\end{array}$ & Material Lot & $\begin{array}{c}\text { Thickness } \\
\text { range for lot, } \\
\text { mm }\end{array}$ & $\begin{array}{c}\text { Avg. } \\
\text { thickness } \\
\text { variation, mm }\end{array}$ & $\begin{array}{l}\text { No. of } \\
\text { foils in } \\
\text { lot }\end{array}$ & Comments \\
\hline \multirow[t]{3}{*}{ Fenn } & EFR301, 303 & 0.018 & 0.009 & 30 & 2007 production \\
\hline & EFR304, 305 & 0.016 & 0.008 & 32 & \\
\hline & EFR306-308 & 0.017 & 0.009 & 37 & \\
\hline \multirow[t]{2}{*}{ Fenn } & MS3 -1,-2,-3 & 0.018 & 0.008 & 24 & all foils, 2006 trials \\
\hline & MS3 -1 -2,-3 & 0.013 & 0.006 & 20 & $\mathrm{~mm}$ \\
\hline \multirow[t]{3}{*}{ Bliss } & GFR240, 241 & 0.030 & 0.012 & 24 & 2004 production \\
\hline & GFR242, 243 & 0.030 & 0.011 & 24 & \\
\hline & GFR244, 245 & 0.040 & 0.009 & 25 & \\
\hline Bliss & Average & 0.033 & 0.010 & & 1993 through 2004 \\
\hline
\end{tabular}

The above results indicate that with use of the Fenn mill a significant improvement in uniformity of average foil thickness was achieved and a relatively small improvement was achieved in the uniformity of thickness within each piece of foil. The uniformity of the average thickness is associated with control of the roll gap and accurate in-process thickness measurements. The variation within the thickness of a single foil is affected in part by the accurate leveling of the rolls, but in the case of iridium alloy foil is primarily related to the uniformity of the sheet material from which the foil is produced. Also shown in Table 4 are values for the MS3 trial foils excluding those foils with initial thickness variations $\geq 0.02 \mathrm{~mm}$ at the starting thickness for rolling on this mill of 0.66 $\mathrm{mm}$. The foils rolled from the more uniform sheet material produce foils with a narrower 
range of thickness. The uniformity of the sheet that is the starting material for foil rolling is constrained by the use of molybdenum covers for rolling of iridium alloy sheets. The prior rolling using molybdenum covers minimizes cracking of the sheets, but also introduces greater variability in thickness of the sheet than would be the case for sheets rolled without the covers. This analysis suggests that the uniformity of foil thickness achieved with the foils from the EFR ingots is close to the practical limit for the current foil production process.

\subsection{CLAD VENT SET}

\subsubsection{Maintenance Production Summary}

Ten prime Clad Vent Sets (CVS) were shipped in September 2007 to Los Alamos National Laboratory as part of the DOE CVS Production Maintenance program. CVS production facility operability was maintained throughout the year. Training of personnel was maintained for all CVS operations during FY07 along with training of two new machinists and one new dimensional inspector. Trend analyses were maintained for all part types. No adverse trends were noted at the end of the year. Eleven (listed below) of twelve surveillances were successfully completed during the year.

Welding Equipment (Laser and Electron Beam)

Destructive Test of Frit Vent Subassembly

Air burn-off/Vacuum Outgas Witness Specimen SEM Evaluation

SEM of Weld Zone on CVS Production Sample

Reinspection (twice)

Tooling Identification and Control

Measuring and Test Equipment Identification and Calibration (twice)

Independent Assessments

Personnel Training Documentation

The remaining CVS surveillance entitled QA Programs will be completed for the CVS dye penetrant area once a DOE-OR Assessment of the RPS Program NDE facilities is complete. The Surveillance and Process Monitoring Plan for RPS Program CVS and CBCF Production Tasks, GPHS-QA-002, is being reviewed and revised for FY08.

\subsubsection{Nonconformance Report, Special Instruction Deviation Request, and Deviation Request Summaries}

One nonconformance report, NCR-CVS-070, was submitted and accepted in FY07. This was for shield cup assembly (SCA), 9754-05-5361, which was dropped two inches during preparation for the surveillance entitled "SEM of Weld Zone on CVS Production Sample". The SCA landed on the weld shield. During straightening of the weld shield, two tabs welds were broken. The tabs are scheduled to be rewelded per standard rework procedures in early FY08.

Two special instruction deviation requests were performed and accepted, which resulted in the submission and acceptance of two deviation requests in FY07. SIDR-CVS-006 
addressed reducing the incidence of weld burnback during the weld shield electron beam butt weld operation. Based on the satisfactory results of this SIDR, the butt welding procedure, GPHS-K-3620, was revised to revision C per deviation request DR-CVS-063. This included revising the Weld Shield Weld Fixture drawing, T2E140484, to revision D to capture tooling improvements made per the SIDR.

SIDR-CVS-007 was used to evaluate the use of the new ONA AE400 Electrical Discharge Machine (EDM) to replace the Elox-Fanuc EDM for cup destructive test sample preparation. EDM parameters were established with non-prime cups. Successful cutting, preparation and testing of samples from FY07 Maintenance Production cup 3625-05-5363 led to the revision of Cup Destructive Test Sample Preparation Procedure GPHS-XF-3624/25A to revision J. This revision was submitted and accepted on deviation request DR-CVS-064.

\subsubsection{Decontamination Cover Tooling}

Back-up decontamination cover blanking tooling was fabricated by Gemcity Engineering and Manufacturing (Dayton, $\mathrm{OH}$ ). The tooling was checked out at Gemcity by blanking parts first from $0.005 "(0.127 \mathrm{~mm})$ thick 304 stainless steel sheet and then production iridium alloy sheet. Both sets of blanks were submitted to ORNL for evaluation. The ORNL evaluation consisted of measuring the as-blanked diameters followed by flattening and re-measuring the diameters, and finally forming decontamination covers and measuring the diameters and heights. The iridium tends to "cup" during blanking whereas the stainless steel does not. This means the average as-blanked diameters for the stainless steel and iridium are very similar, however, after flattening the average iridium diameters are approximately $0.022 \mathrm{~mm}$ larger than the iridium as-blanked diameters and the stainless steel as-blanked and as-flattened diameters. The as-formed average iridium diameters decrease approximately $0.10 \mathrm{~mm}$ from the as-flattened diameter whereas the stainless steel decreases about half that amount $(\sim 0.05 \mathrm{~mm})$. The as-formed iridium height is almost twice that of the stainless steel. This information indicates that stainless steel has very limited use as a surrogate material for iridium component tooling dimensional verifications. Nevertheless, based on the iridium results, the tooling was accepted for ORNL production use.

\subsubsection{Dimensional Inspection Evaluation for Foil Components}

Foil components (frit vent backing and cover discs, weld shields, and decontamination covers) were dimensionally inspected using a new Mitutoyo QVAce 200 vision measuring machine (VMM) along with the current production inspection instrument, an Olympus STM comparator/toolmaker's microscope (STM). These dual inspections were intended to determine whether the new instrument can produce results comparable to the current instrument. If the instruments can be shown to be comparable, then the inspection procedures for each foil part type will be modified (via the deviation request process) to include the use of the new instrument. The STM versus VMM inspections are comparable for many, but not all, of the component attributes. 
Comparisons of the VMM and STM dimensional data for the decontamination covers show good agreement for all dimensional attributes except for the minimum outside diameter (average of $11.530 \mathrm{~mm}$ for the STM vs. $11.515 \mathrm{~mm}$ for the VMM). The VMM minimum diameters are too close to the minimum drawing limit of $11.5 \mathrm{~mm}$. The aforementioned new back-up decontamination cover blanking tooling may be evaluated further in FY08 to determine if the outer diameter minimums and maximums can be adjusted closer to the center of the drawing requirements of $11.6 / 11.5 \mathrm{~mm}$.

Comparisons of the VMM and STM dimensional data for the weld shields show good agreement.

Comparisons of the VMM and STM dimensional data for the frit vent backing and cover discs show good agreement for all dimensional attributes except for the backing disc minimum inside diameter (average of $1.020 \mathrm{~mm}$ for the STM vs. $1.005 \mathrm{~mm}$ for the VMM), the cover disc minimum outside diameter (average of $9.566 \mathrm{~mm}$ for the STM and $9.549 \mathrm{~mm}$ for the VMM) and the cover disc minimum slot inner diameter (average of $6.349 \mathrm{~mm}$ for the STM vs. $6.326 \mathrm{~mm}$ for the VMM). More VMM evaluations will need to be done in FY08 for these problem features.

During the VMM/STM evaluations for the frit vent backing disc parts positional tolerance problems were noted for the central hole diameter to the outside diameter. Follow-up work showed that a damaged brass disc retainer in one set of piercing tooling was the source of the problem. The damaged disc retainer was replaced and the problem was corrected.

\subsubsection{Cup Forming Evaluations}

Build-up of dried and hardened Fiske (Newark, NJ) 604 lubricant on the second-forming die occasionally occurs. This can result in local depressions or grooves in the outer contour of the cup wall and concomitant bulges on the inner contour. These impressions are not preferred. Seven forming lubricants were screened as possible replacements for the current lubricant. Each candidate lubricant was applied (neat) by brush to a die heated to $250^{\circ} \mathrm{C}$, held for 30 minutes, cooled, and then the condition of the lubricant was evaluated. The lubricants and the evaluation results are shown in Table 1. Based on the results both Bostik Never-Seez lubricants (Regular Grade and Pure Nickel Special) will be evaluated further in FY08 by forming cups. 


\section{Table 1. Lubricants Applied to $2^{\text {nd }}$-Form Die Heated to $250^{\circ} \mathrm{C}$ and Held for 30 Minutes}

\begin{tabular}{|c|c|c|}
\hline Lubricant & Carrier & Result \\
\hline Fiske 604 & Mineral oil & Hardened on die \\
\hline $\begin{array}{l}\text { Bostik Never-Seez Regular } \\
\text { Grade }\end{array}$ & $\begin{array}{l}\text { Petroleum } \\
\text { grease }\end{array}$ & Uniform coating, easily removed \\
\hline $\begin{array}{l}\text { Bostik Never-Seez Pure Nickel } \\
\text { Special }\end{array}$ & $\begin{array}{l}\text { Petroleum } \\
\text { grease }\end{array}$ & Uniform coating, easily removed \\
\hline $\begin{array}{l}\text { ZYP Coatings BNW (Boron } \\
\text { Nitride) Paste }\end{array}$ & Water & $\begin{array}{l}\text { Spattering, non-uniform coating, } \\
\text { difficult to remove }\end{array}$ \\
\hline Acheson DAG 137 & Water & $\begin{array}{l}\text { Non-uniform coating, difficult to } \\
\text { remove }\end{array}$ \\
\hline Fuchs Hykogeen 1190 & $\begin{array}{l}\text { Water-soluble } \\
\text { oil }\end{array}$ & Very thin, non-uniform coating \\
\hline Fuchs Hykogeen 1131 & Mineral oil & $\begin{array}{l}\text { Smoked on application, uniform } \\
\text { coating, difficult to remove (varnish- } \\
\text { like) }\end{array}$ \\
\hline Fuchs Lubrodal F360 Jet & Water & $\begin{array}{l}\text { Non-uniform coating, non-wetting, } \\
\text { easily removed }\end{array}$ \\
\hline
\end{tabular}

CVS forming production 'windows' were evaluated further. Thermocouples were inserted into blank assembly TC166 (Fig. 1) containing iridium and also a first-form cup W6 (Fig. 2) containing tungsten (as a surrogate for iridium) to measure cooling rates from the furnace preheat temperature of $925^{\circ} \mathrm{C}$ as they cooled to $600^{\circ} \mathrm{C}$ in conjunction with dies heated to $250^{\circ} \mathrm{C}$ and unheated (ambient temperature $\sim 25^{\circ} \mathrm{C}$ ). No actual forming was performed. Grooves were milled $\sim 1.0 \mathrm{~mm}$ deep in the top of the blank assembly and on the inside bottom of the first-form cup to accommodate the $\sim 1.6 \mathrm{~mm}$ sheath diameter of the Type K thermocouples (T-91N-144BK8A from ARI Industries Inc. Addison, IL). This put the thermocouples in contact with the iridium or tungsten. Also, grooves were milled $\sim 0.78 \mathrm{~mm}$ deep in the $\sim 1.45 \mathrm{~mm}$ thick 304 stainless steel semi-circular covers welded to the assemblies to shield and hold the thermocouples in place. 


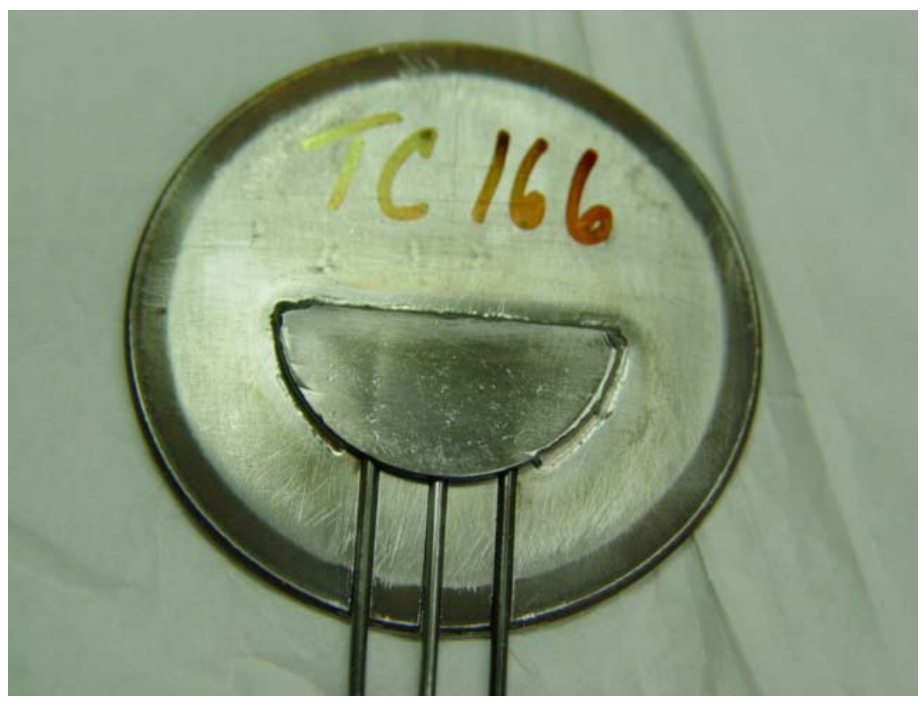

Figure 1. Blank Assembly TC 166 with 3 Type K Thermocouples.

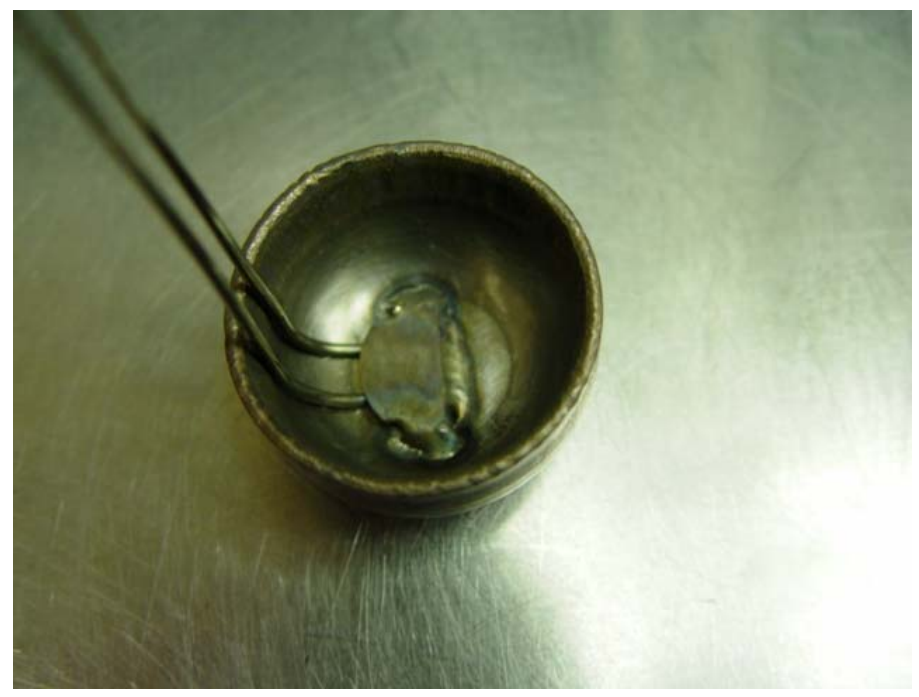

Figure 2. First-Form Cup W6 with 2 Type K Thermocouples.

Initially, thermocouple electrical grounding problems produced erratic results. These grounding problems were resolved by replacing a $10 \Omega$ resistor with a $10 \mathrm{k} \Omega$ resistor and adding ground wires for the stainless steel sheaths. Data were collected at a rate of $1 \mathrm{~Hz}$ (point per second) using LabVIEW version 7.1 (National Instruments Corporation Austin, TX). The cup forming set-up (no actual forming) average cooling rates from $900^{\circ} \mathrm{C}$ down to $600^{\circ} \mathrm{C}$ are summarized in Table 2. These temperatures were selected because $900^{\circ} \mathrm{C}$ is the minimum forming preheat temperature and $600^{\circ} \mathrm{C}$ is considered a good minimum actual forming temperature (sufficient ductility and strength). 
Table 2. Cup Forming Set-Up Average Cooling Rates from $900^{\circ}$ to $600^{\circ} \mathrm{C}$

\begin{tabular}{|l|c|l|c|}
\hline \multicolumn{1}{|c|}{$\begin{array}{c}\mathbf{1}^{\text {Tst}} \text {-Fooling Condition } \\
\text { contact }\end{array}$} & $\begin{array}{c}\text { Cooling } \\
\text { Rate }\left({ }^{\circ} \mathbf{C} / \mathbf{s}\right)\end{array}$ & $\begin{array}{c}\text { 2nd-Form } \\
\text { Tooling Condition }\end{array}$ & $\begin{array}{c}\text { Cooling } \\
\text { Rate }\left({ }^{\circ} \mathbf{C} / \mathbf{s}\right)\end{array}$ \\
\hline $\begin{array}{l}\text { Die at } 250^{\circ} \mathrm{C} \text {, blankholder } \\
\text { Die at room temperature, no } \\
\text { blankholder contact }\end{array}$ & 7 & $\begin{array}{l}\text { Die at } 250^{\circ} \mathrm{C}, \text { no punch } \\
\text { contact }\end{array}$ & $8-9.5$ \\
\hline $\begin{array}{l}\text { Die and punch at } 250^{\circ} \mathrm{C} \text { with } \\
\text { blankholder contact }\end{array}$ & $12-18$ & $\begin{array}{l}\text { Die at room temperature, } \\
\text { no punch contact }\end{array}$ & $\begin{array}{l}\text { Die and punch at } 250^{\circ} \mathrm{C} \\
\text { with punch contact }\end{array}$ \\
\hline $\begin{array}{l}\text { Die at room temperature, punch } \\
\text { at } 250^{\circ} \mathrm{C} \text { with blankholder } \\
\text { contact }\end{array}$ & NA & $\begin{array}{l}\text { Die at room temperature, } \\
\text { punch at } 250^{\circ} \mathrm{C} \text { with } \\
\text { punch contact }\end{array}$ & $18-30$ \\
\hline $\begin{array}{l}\text { Die and punch at room } \\
\text { temperature with blankholder } \\
\text { contact }\end{array}$ & $10-16$ & $\begin{array}{l}\text { Die and punch at room } \\
\text { temperature with punch } \\
\text { contact }\end{array}$ & $22-66$ \\
\hline
\end{tabular}

Note: Parts preheated to $925^{\circ} \mathrm{C}$ minimum and data collection at 1 point per second (Hz).

The cooling rate test runs with no blankholder $\left(1^{\text {st }}\right.$-form $)$ or punch $\left(2^{\text {nd }}-\right.$ form $)$ contact have the slowest cooling rates, ranging from $7^{\circ} \mathrm{C}$ to $9.5^{\circ} \mathrm{C}$, as expected. The die (room temperature or heated to $250^{\circ} \mathrm{C}$ ) cools the blank assembly ( $1^{\text {st }}$-form tooling) or $1^{\text {st }}$-form cup ( $2^{\text {nd }}$-form tooling) from the bottom side (thermocouples are on top) only, thus producing slow cooling rates. Also the $1^{\text {st }}$-form tooling tends to produce a slower cooling rate than the corresponding $2^{\text {nd }}$-form tooling because the die and blankholder contact the blank assembly only on the outer edges, whereas, there is more die and punch contact with the $2^{\text {nd }}$-form tooling. It is possible that the $2^{\text {nd }}$-form cooling rates are higher at least partly because of the approximately $20 \%$ higher thermal conductivity of the tungsten in the $1^{\text {st }}$-form cup versus the iridium in the blank assembly.

The $2^{\text {nd }}$-form tooling set-up at room temperature with punch contact series was done last and the largest number of runs were done in this series. By the time this series was completed enough experience had been gained to apply the most punch pressure which meant the most tooling contact and, therefore, high cooling rates. With this disclosure in mind the $250^{\circ} \mathrm{C}$ tooling temperature may offer negligible benefit in reducing the tooling chill or quench versus room temperature tooling. A typical set of runs for the $2^{\text {nd }}-$ form tooling set-up at room temperature with punch contact series is shown in Fig. 3. This shows that the furnace preheat at $925^{\circ} \mathrm{C}$ is complete in less than 3 minutes indicating that the required $10 \pm 2$ minutes for CVS cup forming is very conservative. The cooling rates in Table 2 and the cooling profiles on the right side of the Figure 3 graph indicate that forming must occur within 5 to 10 seconds after removal from the furnace. These results are consistent with production experiences. 


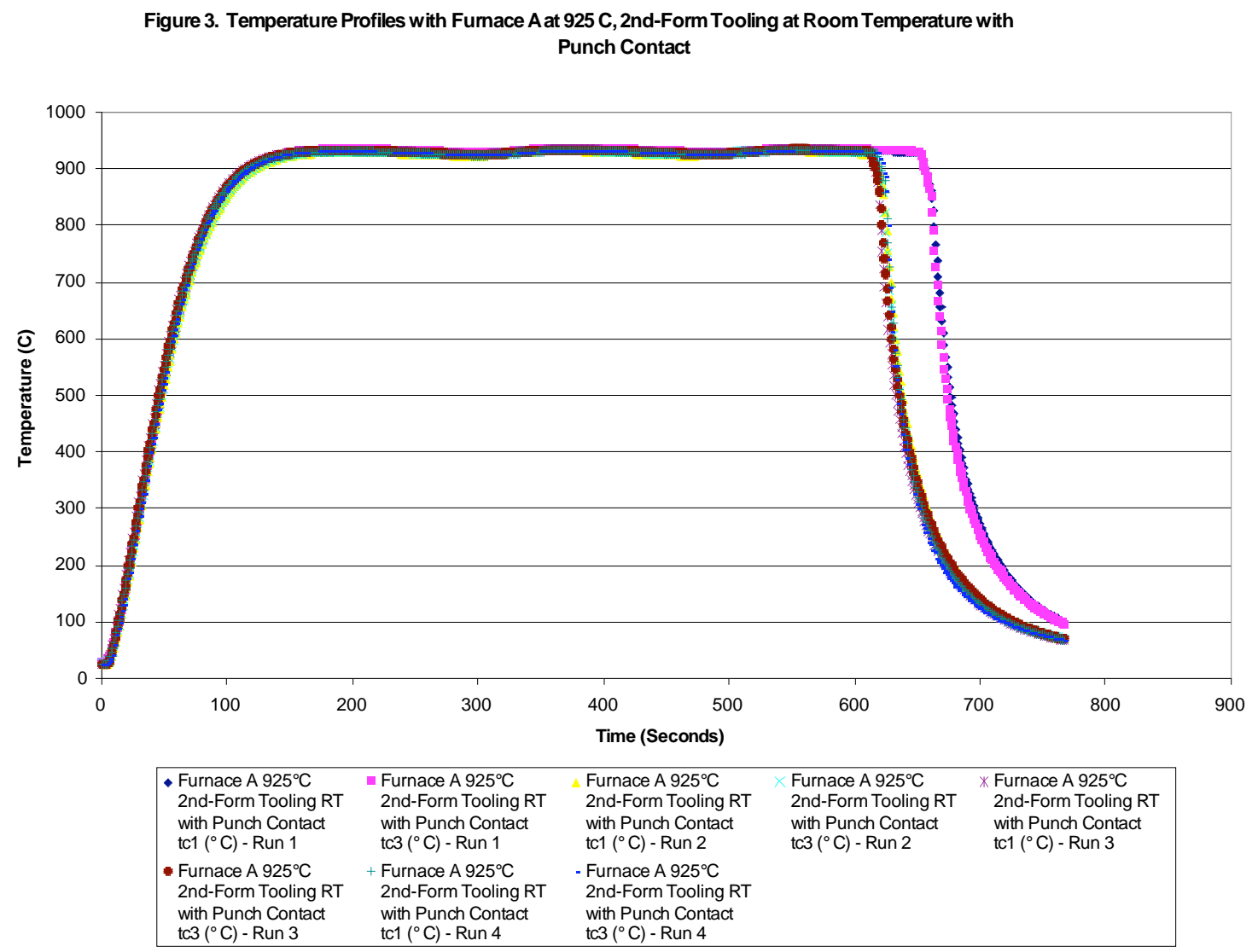

The results from the forming set-up cooling rate evaluations and the lubricant evaluations will be used for follow-up work in FY08. Blank assemblies will be $1^{\text {st }}$-formed and $2^{\text {nd }}$ formed with different combinations of $250^{\circ} \mathrm{C}$ and room temperature tooling conditions, e.g. room temperature die and room temperature punch, room temperature die and $250^{\circ} \mathrm{C}$ punch, etc. The punch-to-die clearances will increase or decrease as much as $0.002 "$ $(0.051 \mathrm{~mm})$ from the standard clearances with the punches and dies at $250^{\circ} \mathrm{C}$. During $2^{\text {nd }}$-forming the lubricant (Bostik Never-Seez Regular Grade, Bostik Never-Seez Pure Nickel Special, and Fiske 604) evaluations will be combined as well. Later work will evaluate changes in forming speeds. 


\subsubsection{Carbon and Oxygen Back-up Analytical Qualifications}

Efforts continued in FY07 to qualify a back-up source for carbon and oxygen analytical testing. The primary source for carbon and oxygen in iridium analyses is the Oak Ridge Y-12 Plant. The instruments qualified for RPS Program use at Y-12 are a LECO Corporation (St. Joseph, MI) CS400 and a TC436 for carbon and oxygen, respectively. After numerous inquiries Anderson Laboratories, Inc. (Greendale, WI) was selected for evaluation as a potential back-up for carbon and oxygen in iridium analytical testing.

Draft procedures MST-MatP-SOP-110 for carbon and MST-MatP-SOP-111 for oxygen were sent to Anderson Laboratories for use during the initial evaluation of iridium powder samples. Good agreement was shown between the Y-12 and Anderson results for these powder samples. The draft procedures were modified based on input from both Anderson and LECO along with a visit to Anderson. The evaluations were then continued for powder samples as well as foil, blank, and cup samples over two time periods referred to as "Week 1" and "Week 2".

Some anomalies in the carbon results were encountered during this testing. These were attributed to a bad electrical contact that has been replaced in the TF- 1 tube furnace used for bake-out of crucibles. Also a new $2^{\text {nd }}$-generation low level infrared detection cell was installed in the LECO CS-600 instrument in late August 2007. A draft procedure change was made for this. Follow-up testing will be done in FY08 to confirm the instrument is operating well and to replace the anomalous results.

Disparities in the oxygen results were encountered during the "Week 1" and "Week 2" analyses.

Anderson replaced their LECO TC-436DR instrument with a new LECO TC-600 instrument in late August 2007. A draft procedure change was made for the new instrument. Additional oxygen analyses will be done at Anderson in FY08.

\subsubsection{Frit Vent Powder Evaluation}

The three production powders, lot 92-0035-jar 6, lot 21-012800-jar A, and lot 91-0087jar 4C, were evaluated along with five non-prime powders to see if in-process measurements could be used to discern "good" from "bad" frit vent powder. Forty seven frit vent assemblies (non-prime and prime) were fabricated and measured to evaluate height (thickness) changes during processing for these eight different powders. The data indicate only a good correlation, 0.90 , between the as-loaded powder thicknesses versus the post-sinter powder thicknesses. Surprisingly there is poor correlation, 0.20 , between the as-loaded powder thicknesses and the post-diffusion bond powder thicknesses. The next-highest correlation, 0.69, was between the initial post-diffusion bond powder thicknesses and the initial post-diffusion bond flow rates.

It appears that powder with excessive fines such as lot $02 \mathrm{ROO} / 34 \mathrm{~A} 2$ - jar $2 \mathrm{~A}$ yields unacceptably thin as-sintered powder thicknesses of $0.264 \mathrm{~mm}$ or less. Acceptable assintered powder thicknesses range from 0.302 to $0.424 \mathrm{~mm}$. Unacceptable post-sinter 
densities are greater than $5.2 \mathrm{~g} / \mathrm{cc}$ (relative density greater than 23\%) while acceptable post-sinter densities range from 3.3 to $4.6 \mathrm{~g} / \mathrm{cc}$ (relative density of $14 \%$ to $20 \%$ ). No other attributes or parameters were found, other than the already-specified powder requirements of chemistry and sieved particle size, for use as predictors or screens to find powder acceptable for FVA use.

Graphite sintering tooling was made from POCO Graphite (Decatur, TX) grade DFP-1 and Graphtek LLC (Buffalo Grove, IL) grade GM-10 in an effort to address the problem of iridium powder sticking to the graphite tooling instead of the frit vent backing disc during sintering. The intent was to find a material, machined to the required surface finish of $16 \mu \mathrm{in} \vee \mathrm{rms}$, that would perform better (lower incidence of iridium powder sticking to the graphite pins and/or bushings during sintering) than the currently-specified ATJ graphite. Dimensional and visual (10X to 20X) inspections of the new sintering tooling components showed the tooling surfaces to be rougher than desired. This may be pursued further in FY08 with different suppliers.

\subsection{IRIDIUM POWDER AND INVENTORY MANAGEMENT}

The purpose of this work is to manage an iridium inventory for all heat source contractors with emphasis on the significant quantities of iridium located at LANL, INL, and ORNL and to maintain a no-change iridium inventory through an annual write-off of inventory and processing losses.

\subsubsection{Iridium Demand and Supply Schedule}

The demand and supply schedule, prepared for contingent planning purposes, presents a strategy to assess the availability of iridium for all improving and producing activities by projecting future demands. An adequate inventory needs to be maintained to meet the needs of the National Aeronautics and Space Administration (NASA), and defense missions. The following table indicates that enough iridium will be available for these missions.

The first part of the table shows the estimated production demand factors for prime blanks and foil. The schedule of produced blanks and foil represents the quantity and timing for delivery or storage at ORNL. The ingots from new material represent the quantity produced from new iridium powder to make either blanks or foil. These ingots must be produced on a timely basis to meet the lead-time requirement to produce and deliver or store the blanks and foil.

The production of blanks and foil produces recyclable iridium material that can be placed back into the production process at ORNL. A greater economic benefit is realized by using recycled material, since the need to purchase powder from an outside vendor is reduced. 
Refinable iridium scrap is also generated from the production of blanks and foil. This scrap is sent to a commercial refinery when a sufficient accumulation occurs at ORNL, funding is available for the refining, and it makes economic sense based on a comparison of refining costs to that of new material.

Process losses of iridium occur during the working of the material at ORNL, LANL, and INL. Losses also occur during the refining process. These inventory losses are writtenoff annually.

The information contained within the table can be summarized as follows. With the completion of the refining contract in FY 2007, there will be an adequate supply of iridium powder to produce the hardware for NASA, and defense missions and $98 \mathrm{~kg}$ will remain at the beginning of FY 2011.

\section{Demand and Supply Schedule Shows Factors and Provides Strategy to Ensure an Adequate Supply of Iridium Powder for MMRTG, Stirling Generator Program, and Defense Missions}

\begin{tabular}{|c|c|c|c|c|}
\hline \multirow[b]{2}{*}{ Factors and strategy } & \multicolumn{4}{|c|}{ U. S. Government fiscal years } \\
\hline & FY 2007 & FY 2008 & FY 2009 & FY 2010 \\
\hline \multicolumn{5}{|c|}{ Production-demand factors } \\
\hline Produced blanks ${ }^{1}$ & 30 & 30 & 30 & 30 \\
\hline Ingots from new material & 0 & 0 & 1 & 0 \\
\hline Ingots from recyclable material & 0 & 0 & 0 & 0 \\
\hline Produced foil $\left(\mathrm{m}^{2}\right)$ & 0.4 & 0 & 0 & 0 \\
\hline \multicolumn{5}{|c|}{ Refining and process losses (kg) } \\
\hline Refining loss & 0 & 0 & 0 & 0 \\
\hline Processing losses & 1.6 & 3.0 & 3.0 & 3.0 \\
\hline \multicolumn{5}{|c|}{ Supply strategy $(\mathrm{kg})^{2}$} \\
\hline Beginning balance of powder & 43 & 83 & 123 & 104 \\
\hline Receipt of refined powder & 40 & 42 & 0 & 0 \\
\hline Receipt of purchased powder & 0 & 0 & 0 & 0 \\
\hline
\end{tabular}




\subsubsection{Annual Write-Off}

The annual fiscal year 2007 write-off of iridium inventory was completed in June. A total of $3.4 \mathrm{~kg}$ of iridium was written off as a normal operating loss. The write-off appropriately reduced the non-fund iridium inventory. This $3.4 \mathrm{~kg}$ loss was considered a normal operating loss compared to the history of iridium losses during the past several years.

\subsubsection{Iridium Accountability Reviews}

The review at ORNL was conducted in May. The purpose of this review was to evaluate the accountability, physical inventory, and security of iridium at ORNL. It was concluded that the accountability, physical inventory, and security for the iridium was in place and operating in a proper manner. No recommendations were necessary.

The review at LANL was conducted in August. The purpose of this review was to evaluate the accountability, physical inventory, and security of iridium at LANL. It was concluded that the accountability, physical inventory, and security for the iridium was in place and operating in a proper manner. Two recommendations were proposed to enhance the present accountability, physical inventory, and security system.

\subsubsection{Shipment of Iridium}

The shipment of ten (10) iridium alloy clad vent sets to LANL departed ORNL on September 18 and arrived at LANL on September 19. The security seals on the shipping container were intact upon arriving at LANL. U. S. Department of Energy Transfer Voucher No. 100-OR4-NS4-128 dated October 30 was issued to properly account for this shipment. 


\section{BASE TECHNOLOGY TASKS}

\subsection{ALLOY CHARACTERIZATION}

The objective of this task is to characterize the mechanical and metallurgical properties of metallic materials that are of interest to the RPS Program. Summarized below are the results of our activities during FY 2007.

\subsection{1 "Low-temperature" tensile impact ductility of DOP-26 iridium}

The purpose of this study was to extend the database of the tensile impact ductility of DOP-26 iridium down to lower temperatures $\left(500-900^{\circ} \mathrm{C}\right)$ at a bullet velocity of $61 \mathrm{~m} / \mathrm{s}$ (which corresponds to an engineering strain rate of $\sim 10^{3} \mathrm{~s}^{-1}$ ). During FY 2007, additional tensile impact tests were performed so that data from at least 4 specimens were obtained at each grain size $(23,30$, and $35 \mu \mathrm{m})$ and temperature $\left(500,600,700,800\right.$ and $\left.900^{\circ} \mathrm{C}\right)$ of interest. Ductility increased with increasing test temperature for all three grain sizes. Associated with this increase in ductility with increasing temperature is a change in the fracture mode from intergranular to transgranular.

\subsubsection{Effects of temperature, strain rate, and orientation on the tensile strength and ductility of DOP-26 iridium}

Tensile tests were performed at temperatures ranging from room temperature to $1090^{\circ} \mathrm{C}$ and strain rates ranging from $1 \times 10^{-3}$ to $50 \mathrm{~s}^{-1}$. Prior to testing, the specimens were given a vacuum recrystallization anneal of 1 hour at $1375^{\circ} \mathrm{C}$. Testing was performed in orientations parallel and perpendicular to the rolling direction of the sheet from which the specimens were fabricated. Room temperature testing was performed in air, while testing at elevated temperatures was performed in a vacuum better than $1 \times 10^{-4}$ Torr. The yield stress (YS) and the ultimate tensile stress (UTS) decreased with increasing temperature and increased with increasing strain rate. Between 600 and $1090^{\circ} \mathrm{C}$, the ductility (\% elongation) showed a slight increase with increasing temperature. Within the scatter of the data, the ductility did not depend on the strain rate. The reduction in area (RA), on the other hand, decreased with increasing strain rate. The YS and UTS values did not differ significantly for the longitudinal and transverse specimens. The ductility and RA values of the transverse specimens were marginally lower than those of the longitudinal specimens. Ductility is not reduced at intermediate temperatures (e.g., $750^{\circ} \mathrm{C}$ ) when the strain rate becomes sufficiently high. It should be noted, however, that the maximum strain rate in the present study was $50 \mathrm{~s}^{-1}$. Additional testing is needed to obtain data at higher strain rates (to $\sim 1000 \mathrm{~s}^{-1}$ ) for use as inputs for safety analyses of DOP-26 capsules.

\subsubsection{Effects of copper on the tensile impact ductility of DOP-26 iridium}

The effects of $\mathrm{Cu}$ concentrations in the range 7-42 wppm on the tensile impact ductility of DOP-26 iridium were investigated. Our results indicate an embrittling effect of $\mathrm{Cu}$ when present at levels exceeding about 24 wppm $\mathrm{Cu}$. These $\mathrm{Cu}$-containing alloys have both lower ductilities and greater amounts of intergranular fracture compared to DOP-26 iridium containing no added copper. At a lower level (7 wppm) of added $\mathrm{Cu}$ the ductility 
is significantly (factor of 2) higher than in alloys containing 24-42 wppm $\mathrm{Cu}$. The ductility of the alloy doped with 7 wppm $\mathrm{Cu}$ is $19 \pm 6 \%$ (average of 8 specimens), which exceeds the minimum required $(13.5 \%)$ for qualification of the iridium powder used in DOP-26 production. It also compares favorably with the average ductility $(23 \pm 5 \%)$ of 21 ingots of DOP-26 iridium produced during the Cassini mission. Grain size differences appear not to be responsible for the observed $\mathrm{Cu}$ effects because, after a given heat treatment, all the $\mathrm{Cu}$-containing alloys had similar grain sizes as DOP-26 iridium containing no added copper. Analyses of grain-boundary chemistry using Auger spectroscopy as well as quantitative analyses of the precipitates seen in the $\mathrm{Cu}$-containing alloys are needed to identify the physical mechanism(s) responsible for the $\mathrm{Cu}$-induced embrittlement.

\subsubsection{Effects of oxygen on the elevated-temperature tensile ductility of Ta-10W}

The effects of oxygen on the tensile ductility of Ta-10W were investigated at temperatures to $1100^{\circ} \mathrm{C}$ and different strain rates $\left(\sim 10^{-3}-10^{3} \mathrm{~s}^{-1}\right)$. At all temperatures, the general trend is that ductility decreases with increasing oxygen concentration in the alloy and partial pressure in the test environment. Associated with this drop in ductility is a change in the fracture mode from ductile transgranular to brittle intergranular. The oxygen concentration or partial pressure at which ductility decreases sharply (the ductile-to-brittle transition, DBT) depends on the test temperature and the strain rate: the data obtained so far indicate that impact ductility is relatively insensitive to test temperatures in the range $300-1100^{\circ} \mathrm{C}$, with the embrittling effect of oxygen similar at all these temperatures. At room temperature, however, oxygen has a more severe embrittling effect. This behavior is opposite to that observed at slow strain rates $\left(\sim 10^{-3} \mathrm{~s}^{-1}\right)$ where the embrittling effect of oxygen is more severe at elevated temperatures than at room temperature. It appears that this difference is related to the kinetics of oxygen transport to crack tips. Limited impact tests were performed on $\mathrm{T}-111$ at temperatures to $500^{\circ} \mathrm{C}$ as a function of absorbed oxygen in the alloy. The results indicate that, at room temperature, the embrittling effect of oxygen is less severe in T-111 than in Ta-10W, but this difference decreases as the temperature increases. Additional experiments are needed to understand the underlying mechanism of this difference.

\subsection{ORNL CHARACTERIZATION OF MIN-K TE-1400}

\subsubsection{Introduction}

The assistance of ORNL was requested to characterize the thermomechanical properties of Thermal Ceramics Min-K 1400TE material, hereafter referred to as Min-K, in support of its Multi-Mission Radioisotope Thermoelectric Generator (MMRTG) Program. In particular, ORNL was tasked with the determination of the high temperature compressive strength and stress relaxation behavior of Min-K up to $900^{\circ} \mathrm{C}$ in helium along with the formulation of a general model for the mechanical behavior exhibited by Min-K. Testing was to consist of general high temperature compressive mechanical testing, isothermal stress relaxation testing, and stress relaxation testing of samples exposed to a thermal gradient. 
Previous reports were written for the first two years of the project and can be referenced, "ORNL Characterization of Min-K TE-1400 FY'05" and "ORNL Characterization of Min-K TE-1400 FY'06", describing the initial compression testing performed at room temperature and under various loading rates to determine the required sample sizes and geometries for compressive test specimens and the initial isothermal and gradient stress relaxation testing along with modeling efforts. Additional gradient stress relaxation testing was performed in year two and test equipment was redesigned to facilitate longerterm testing to further characterize the elevated temperature mechanical behavior of Min$\mathrm{K}$ TE-1400. Additionally, modeling efforts were refined to predict the long-term mechanical behavior of the Min-K material when subjected to a temperature gradient condition.

Work was continued this year to further characterize the elevated temperature mechanical behavior of Min-K TE-1400. Gradient stress relaxation testing was continued to obtain longer-term data of up to one-year duration. Additionally, modeling efforts were continued to predict the long-term mechanical behavior of the Min-K material when subjected to a temperature gradient condition.

\subsubsection{Experimental Procedures}

Gradient stress relaxation testing was continued on 6" diameter, 3" long cylindrical samples. Temperature gradients consisted of $700 / 100^{\circ} \mathrm{C}$ with initial loads of 200 psi. A modified test procedure was used based on the original gradient stress relaxation test procedure and testing was performed using a set-up similar to that previously described. This set-up consists of an electromechanical testing machine (Instron Model 1380) equipped with load and displacement digital controllers, a $35 \mathrm{kN}$ load cell, a heated Inconel platen above and below the sample, and a single zone furnace. An aluminum environmental chamber with helium flow is used for controlling the environment. Loading was performed in strain control utilizing a twelve-step loading scheme with loading every half hour at a rate of $5.56 \%$ strain/hour. Loading was followed by stress relaxation in strain control with testing scheduled to be carried out for up to one-year (8760 hours).

\subsubsection{Results}

At the end of the second year, the four current gradient stress relaxation tests (Gradient Test \#10, \#11, \#13, and \#15) were still on-going. Test \#10, \#11, and \#13 had testing attempted on them to simulate the EDL/MSL Transient Strain Events. Test \#15 was unaltered. Test \#10 and \#11 were ended during year three as described below. Test \#13 and \#15 are still on-going.

Due to a stuck crosshead in the test frame during year two, EDL/MSL testing could not be run on Test \#10, but continued monitoring of the stress relaxation under a fixed displacement was performed. This test was ended after over 9,250 hours due to a platen failure. At its conclusion, this test had been running for over one year and had relaxed to 119 psi. Results for this test are shown in Figure1. 


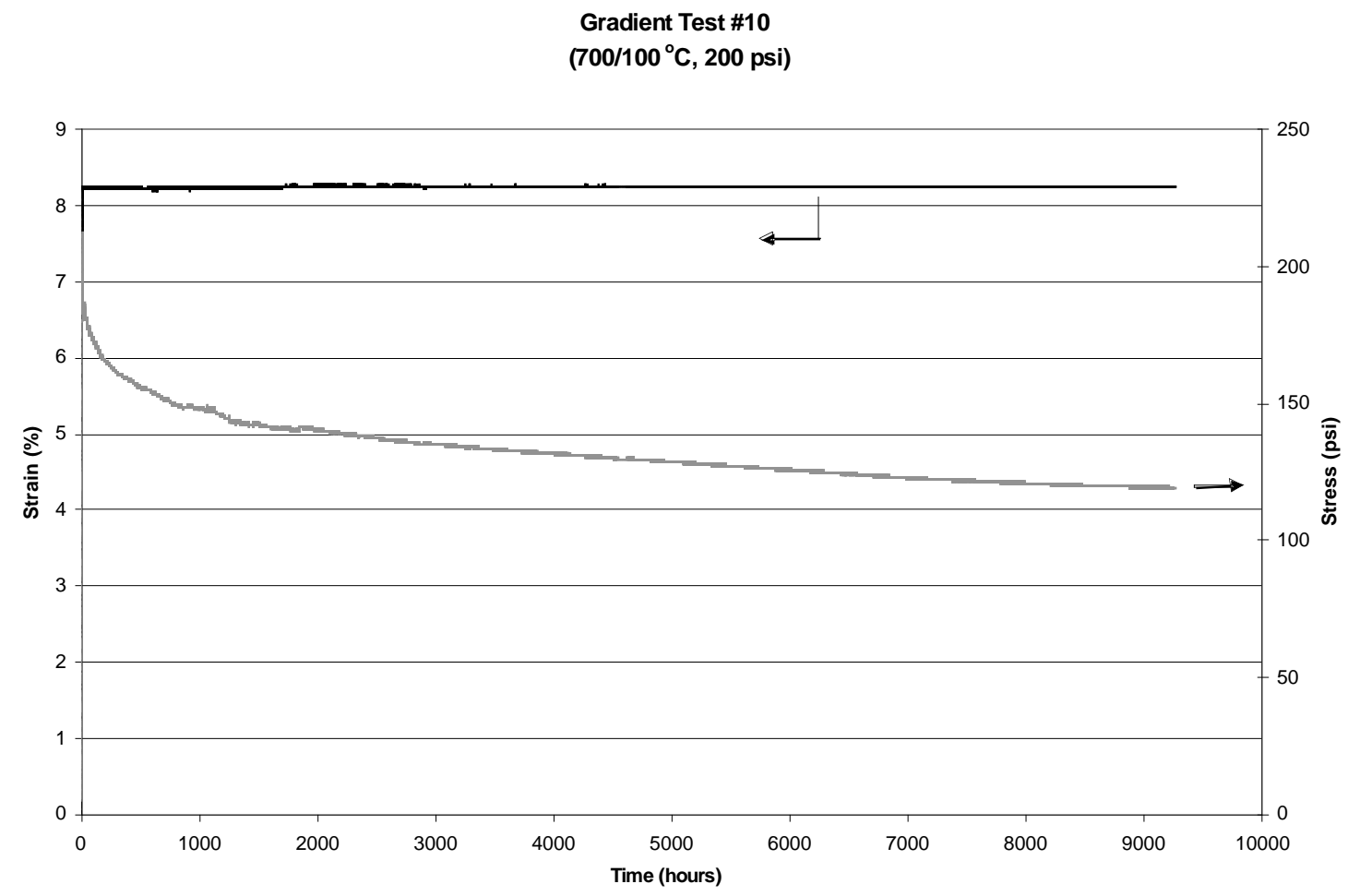

Figure 1. Results from $700 / 100^{\circ} \mathrm{C}$ Gradient Stress Relaxation Test (Test \#10)

EDL/MSL testing was also attempted on Test \#11 during year two. This test was not successful and resulted in the sample being overloaded. After discussion with other program participants, it was decided to attempt an unloading of the specimen back to the original strain level during which nearly all the load was removed and the unloading was stopped with approximately 25 psi remaining on the specimen. The test was then allowed to sit under fixed displacement after these events. The test was continued during year three until it was ended due to a computer failure. At its conclusion, this test had been running for 5,090 hours and had relaxed to 59 psi. Results for this test are shown in Figure 2. 


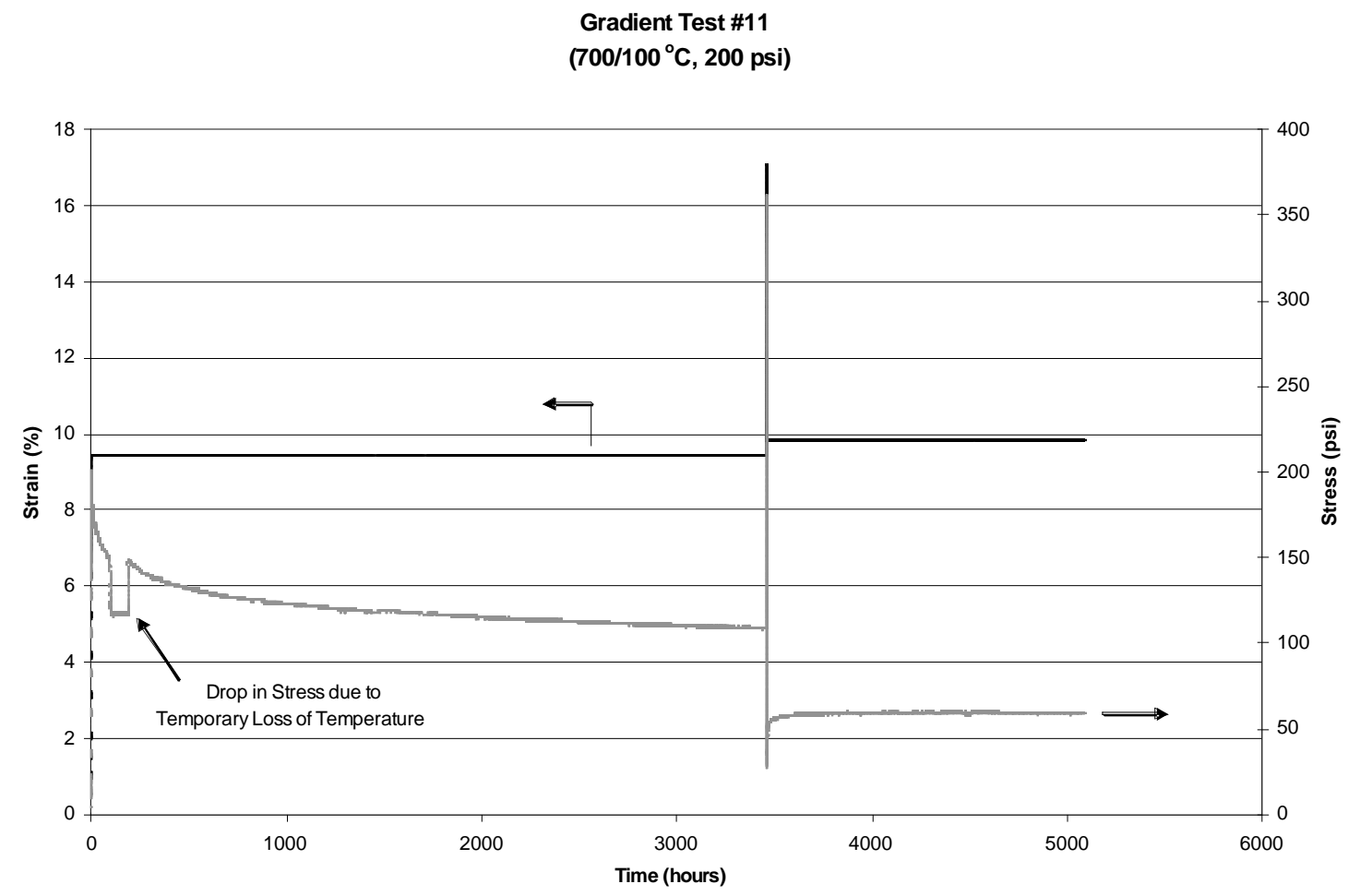

Figure 2. Results from $700 / 100^{\circ} \mathrm{C}$ Gradient Stress Relaxation Test (Test \#11)

EDL/MSL testing was successfully performed on Test \#13 during year two. At the conclusion of the EDL/MSL testing the strain was returned back to the original strain level of $11.493 \%$. This resulted in a change of stress from approximately 110 psi to 118 psi. Following this, the test was put back in hold under fixed displacement. This test has been continued during year three and at the time of the writing of this document; the test had been running for over one year with more than 10,050 hours of exposure and a stress level of 105 psi. Results for this test are shown in Figure 3. Even though the project is completed, this test will continue to run until platen or other frame failure occurs. 


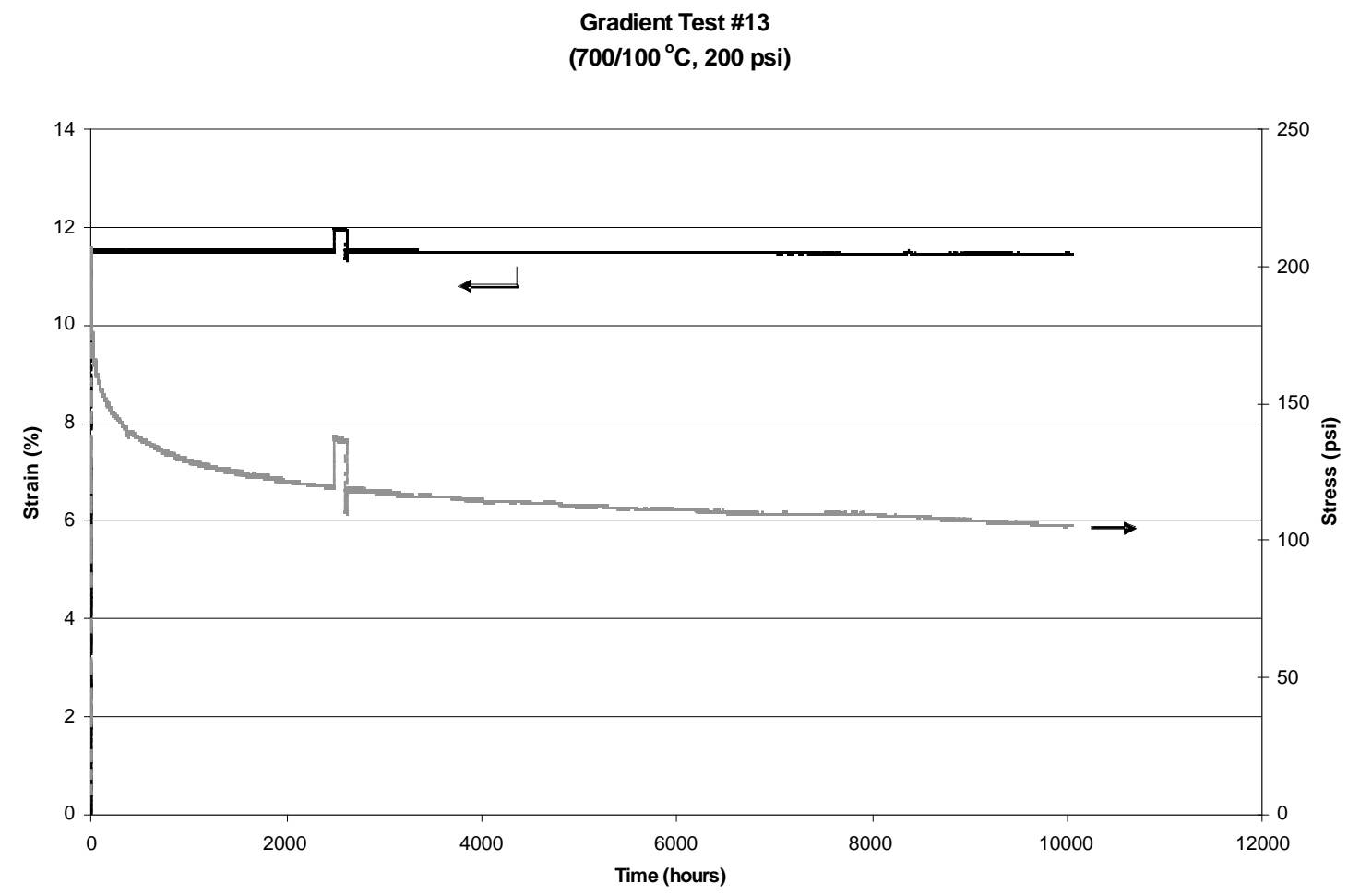

Figure 3. Results from $700 / 100^{\circ} \mathrm{C}$ Gradient Stress Relaxation Test (Test \#13)

Test \#15 has been running unaltered since its start. This test has been continued during year three and at the time of the writing of this document; the test had been running for over one year with more than 9,735 hours of exposure and a stress level of 126 psi. Results for this test are shown in Figure 4. Even though the project is completed, this test will continue to run until platen or other frame failure occurs. 


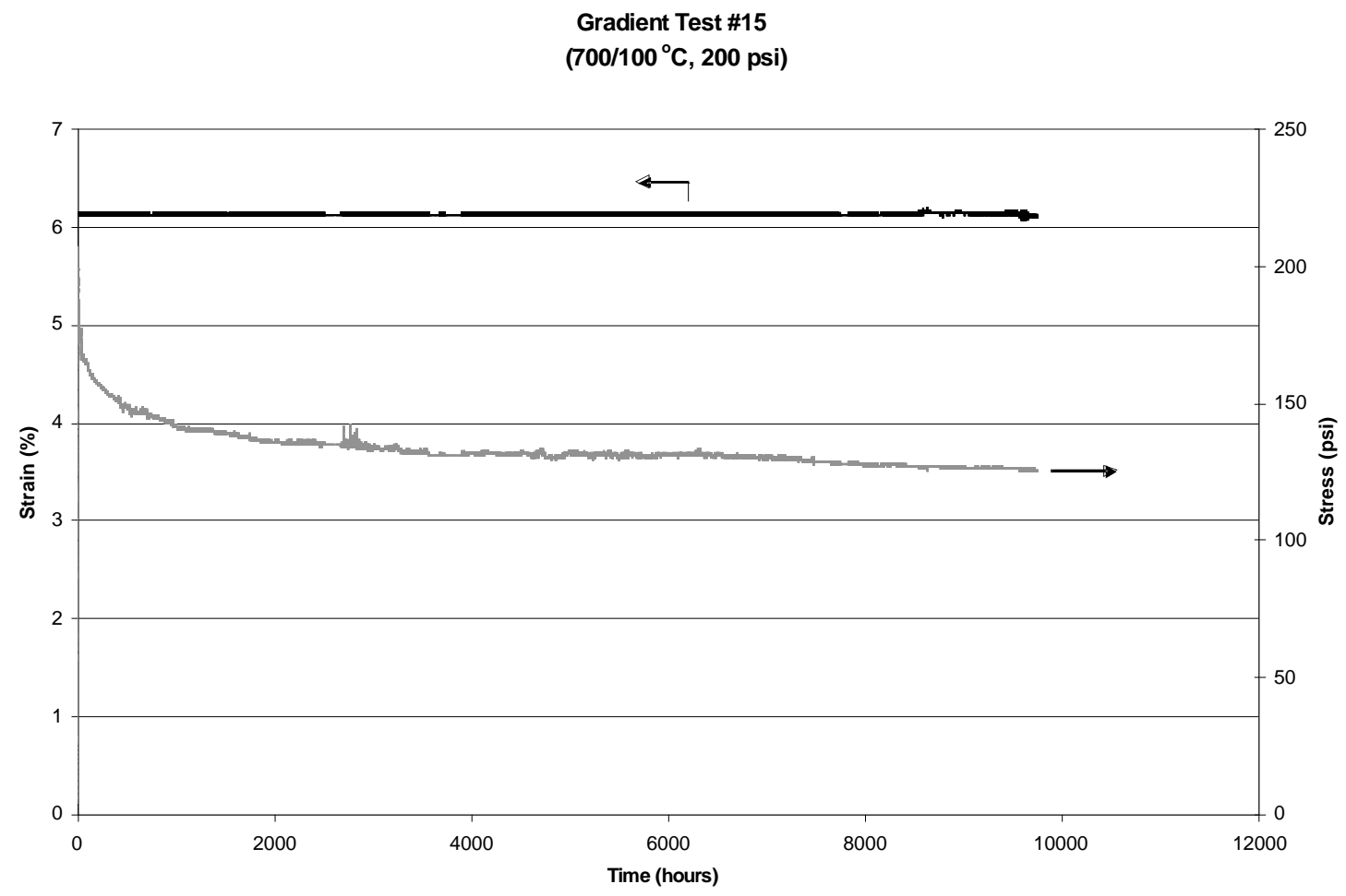

Figure 4. Results from $700 / 100^{\circ} \mathrm{C}$ Gradient Stress Relaxation Test (Test \#15)

Modeling has been pursued independently by the system integrator and ORNL. Currently, ORNL has found that a simple $\log$ function $(\mathrm{y}=\mathrm{a}-\mathrm{b} * \log (\mathrm{x}))$ best fits the long-term gradient stress relaxation data to date as shown in

Figure 5 for Test \#13 and Test \#15. In both cases, an R value of 0.98 was obtained using this function.

a)

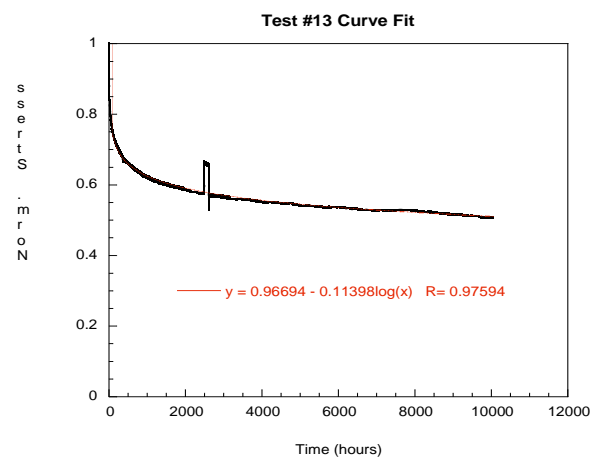

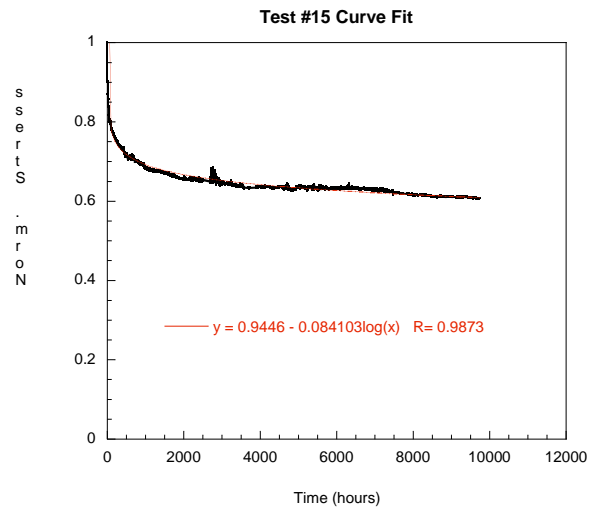

b)

Figure 5. Log Function Curve Fits of Long-Term Gradient Stress Relaxation Data (a - Test \#13, b - Test \#15) 
Also, the effect of fitting various time scales of data for predicting long term behavior was investigated. Fits were made using the same simple log function as above using data from $1,000,2,500,5,000,7,500$, and 9,000 hours. In each case, predictions were made out to 10,000 and 50,000 hours as shown in Figure 6 and Figure 7, respectively.

Test \#13 Curve Fits

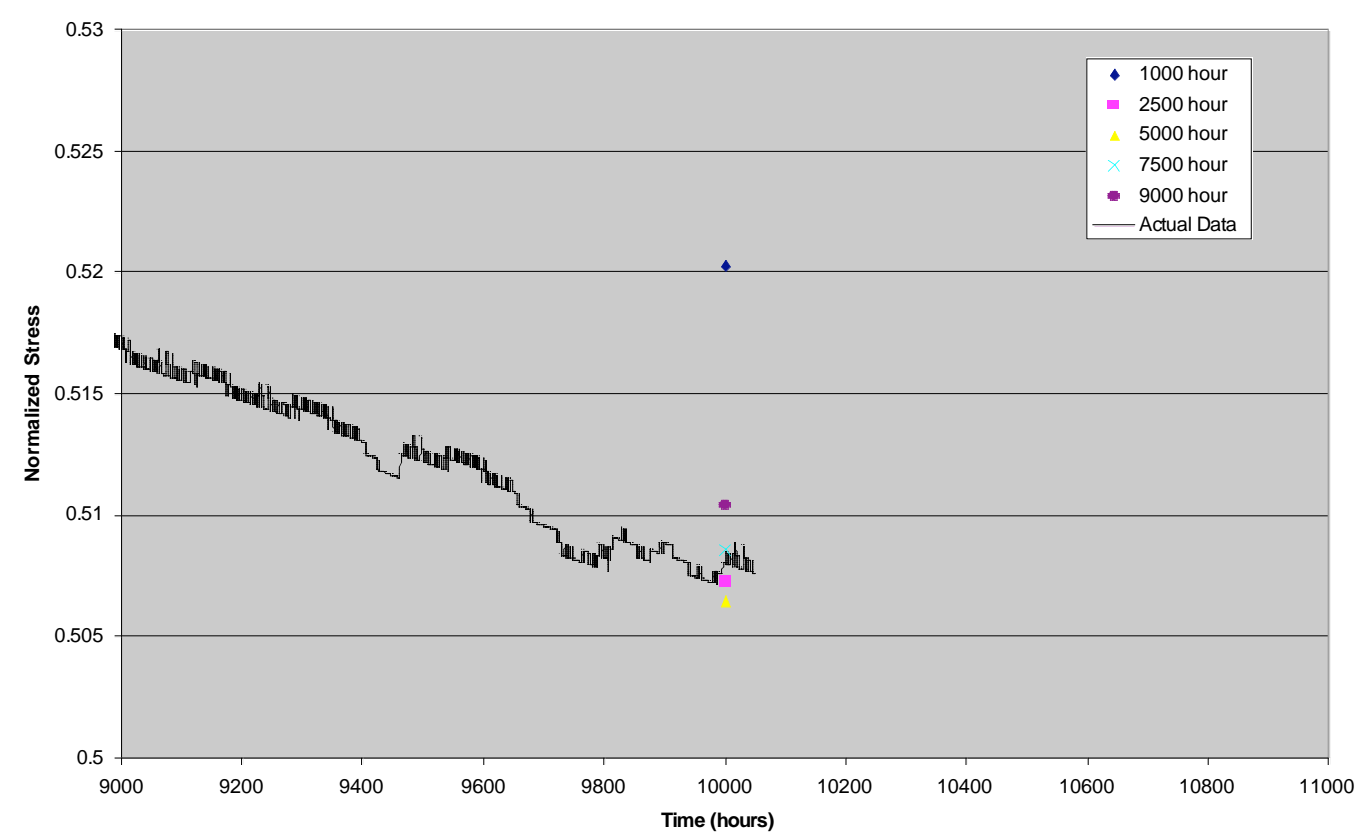

Test \#13 Curve Fits

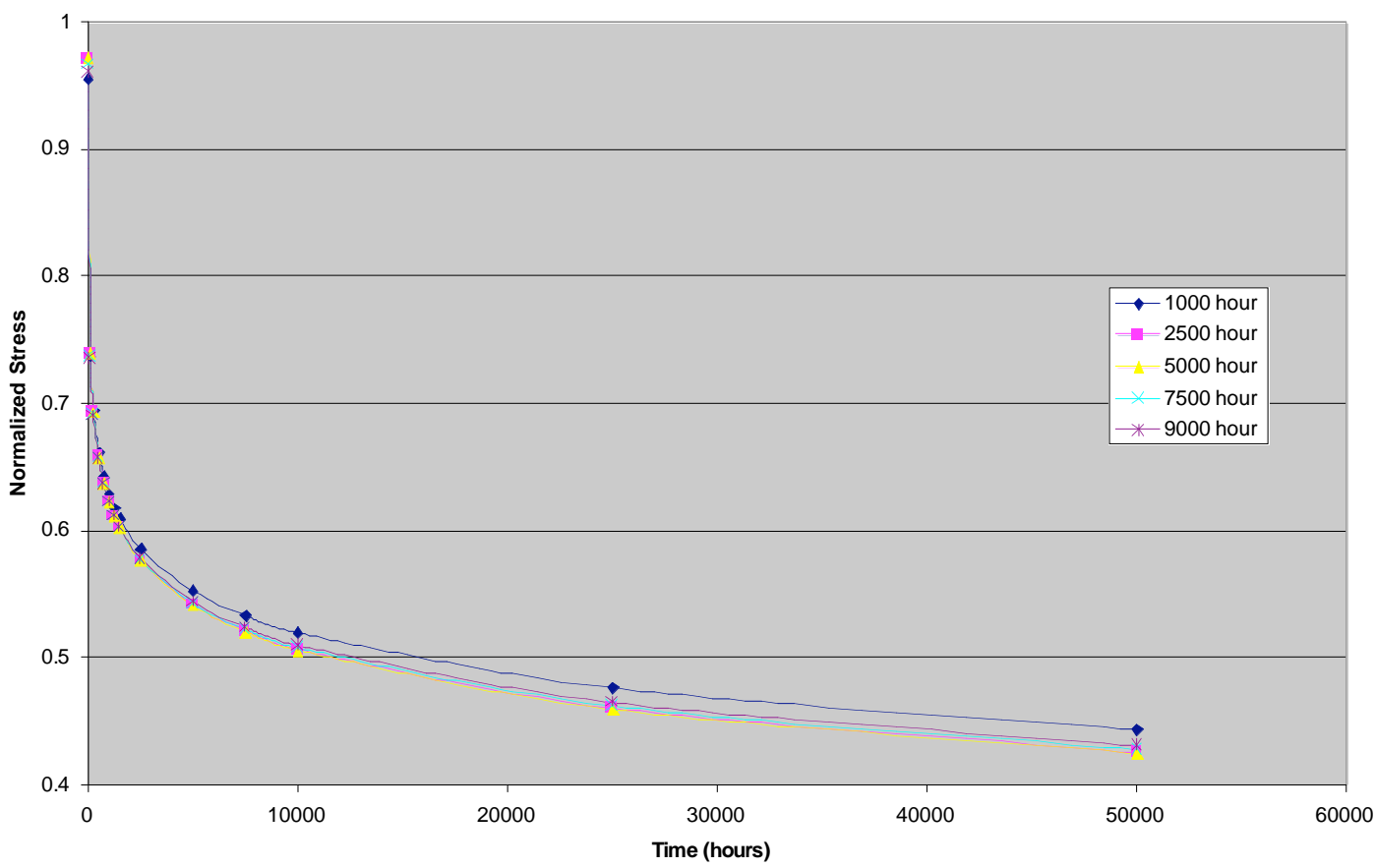

Figure 6. Gradient Test \#13 Log Fit Predictions 


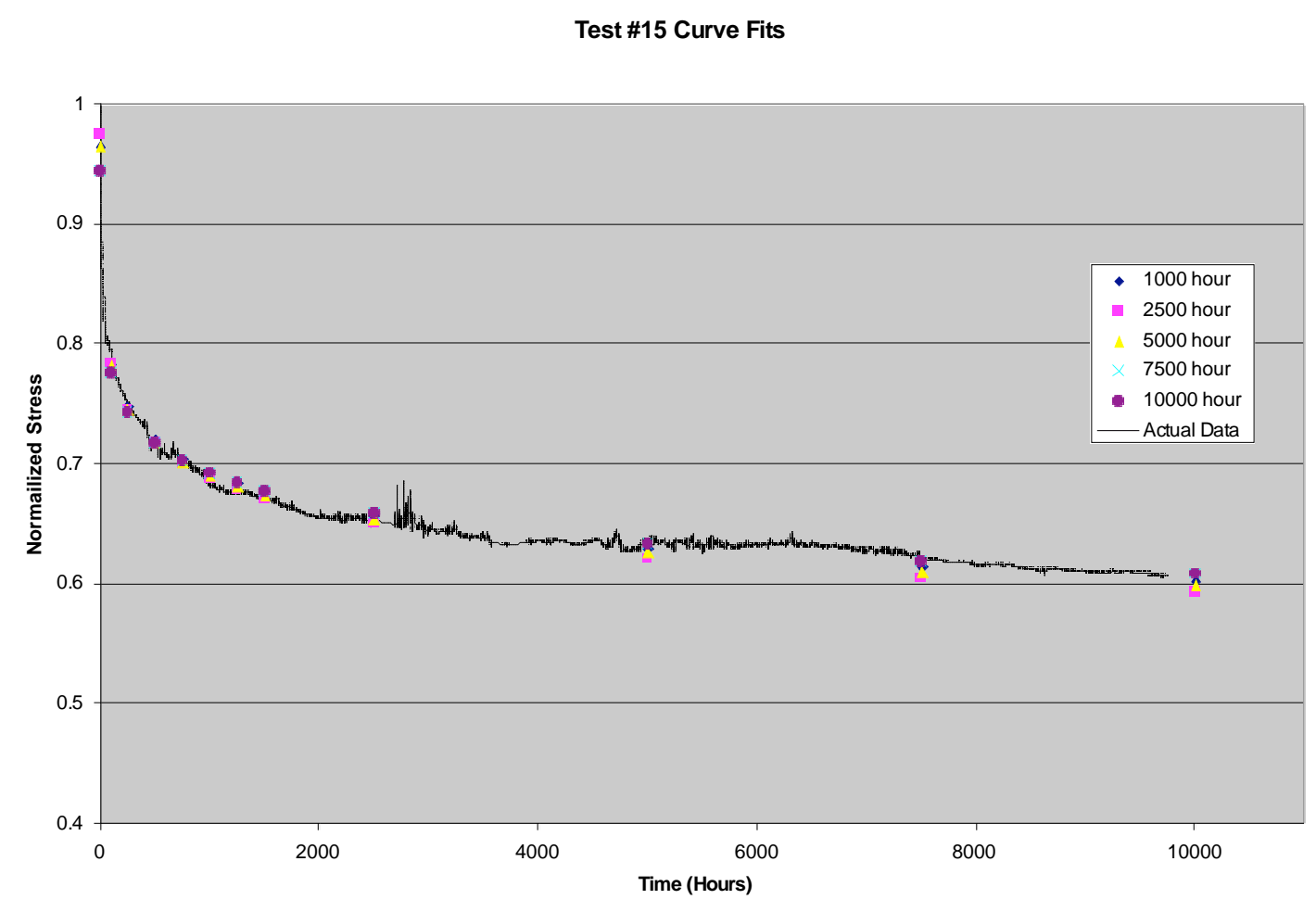

Test \#15 Curve Fits

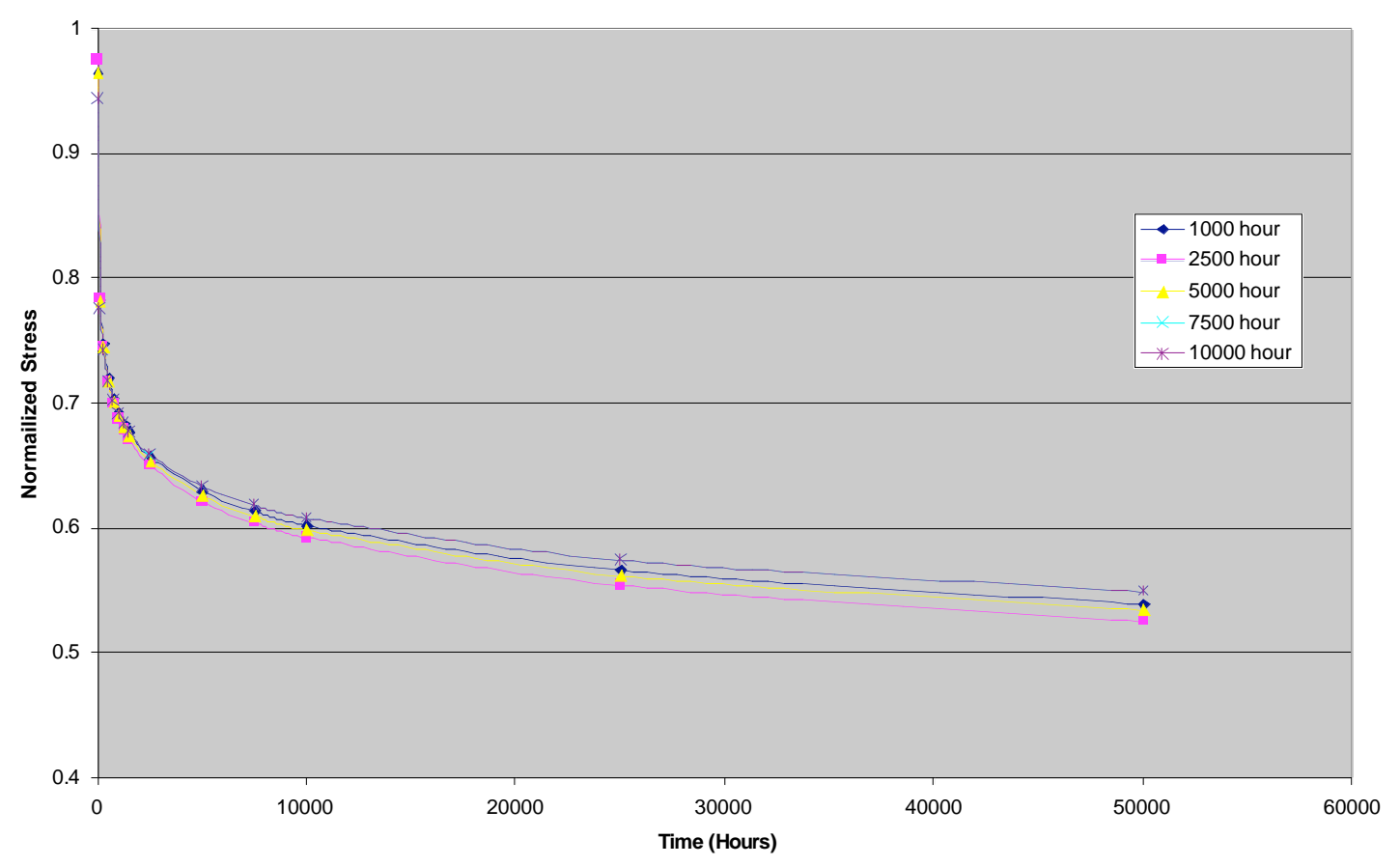

Figure 7. Gradient Test \#15 Log Fit Predictions 
From the current analysis, it appears that data between 5,000 and 7,500 hours is sufficient to predict behavior out to 10,000 hours. Data of less than 5,000 hours tends to under predict the stress relaxation. Data of greater than 7,500 hours accurately predicts the stress relaxation, but does not provide any improvement in the prediction. Therefore it may not be necessary to extend testing to this duration, even for predictions out to 50,000 hours.

\subsubsection{Summary}

During the third year of the project, work was continued to further characterize the elevated temperature mechanical behavior of Min-K TE-1400. The gradient stress relaxation testing from year two was continued to obtain data of up to one-year duration. Two tests were ended during year three, while two tests are still on-going. One test was ended after over 9,250 hours due to a failed platen. A second test was ended due to a computer failure after running for 5,090 hours. The two currently running tests have been running for over 10,050 and 9,735 hours, respectively and will be kept running until platen or other frame failure occurs. Additionally, modeling efforts were continued to predict the long-term mechanical behavior of the Min-K material when subjected to a temperature gradient condition. Modeling has been pursued independently by the system integrator and ORNL with ORNL currently finding that a simple $\log$ function $(y=a-b *$ $\log (\mathrm{x}))$ best fits the long-term gradient stress relaxation data to date. Additionally, it appears that data between 5000 and 7500 hours is sufficient to predict behavior out to 10,000 hours and maybe even for predictions to 50,000 hours. 
ORNL/TM-2008/012

INTERNAL DISTRIBUTION
1. E. P. George
2. J. G. Hemrick
3. J. M. Holladay
4. J. S. Ivey
5-7. J. F. King

\author{
8. R. G. Miller \\ 9. E. K. Ohriner \\ 10. G. R. Romanoski \\ 11. G. B. Ulrich \\ 12. ORNL Laboratory Records-OSTI
}

\title{
EXTERNAL DISTRIBUTION
}

13-19. U. S. DEPARTMENT OF ENERGY, NE-34/Germantown Building, 1000 Independence Avenue S. W., Washington, District of Columbia 20585-1290
W. A. Bohne
L. Edgerly
W. P. Carroll
L. L. Rutger
J. Dowicki
R. L. Wiley
D. Cairns-Gallimore

20. DEPARTMENT OF ENERGY, Oak Ridge Office, Building 4500N, Oak Ridge, TN 37831

S. R. Martin, Jr., Mail Stop 6269

21. IDAHO NATIONAL LABORATORY, P. O. Box 1625, Idaho Falls, ID 83415

K. L. Lively

22. LOS ALAMOS NATIONAL LABORATORY, P. O. Box 1663, NMT-9, MS E502, Los Alamos, NM 87545

C. E. Van Pelt

23-24. ORBITAL SCIENCES CORPORATION, INC., 20030 Century Blvd., Suite 102, Germantown, MD 20874
R. T. Carpenter
E. A. Skrabek

25. URS Washington Division, P. O. Box 5388, Aiken, SC 29804-5388

M. O. Smith 